\title{
A Model of the Near-Surface Circulation of the Santa Barbara Channel: Comparison with Observations and Dynamical Interpretations
}

\author{
LIE-YAUW OEY \\ Atmospheric and Oceanic Science Program, Princeton University, Princeton, New Jersey \\ Clinton Winant and Ed Dever \\ Center for Coastal Studies, Scripps Institution of Oceanography, La Jolla, California \\ WALTER R. JOHNSON \\ U.S. Department of Interior Minerals Management Service, Herndon, Virginia \\ DONG-PING WANG \\ Marine Science Research Center, State University of New York at Stony Brook, Stony Brook, New York
}

(Manuscript received 20 September 2002, in final form 20 June 2003)

\section{ABSTRACT}

\begin{abstract}
Previous studies indicate the importance of wind, wind curl, and density differences in driving the near-surface circulation in the Santa Barbara Channel (SBC). Here model sensitivity experiments and dynamical analyses of the near-surface currents in the SBC are presented. Various approximations of the wind-from coarse-resolution European Centre for Medium-Range Weather Forecasts (ECMWF) archives to a high-resolution dataset that incorporates buoy, oil-platform, and land-based wind stations-are used. In some experiments, observed temperatures at 10 moorings are also assimilated into the model. Model solutions are sensitive to channel-scale $[O(10 \mathrm{~km})]$ wind distribution. Modeled currents forced by the ECMWF wind yield poor results when compared with observations. The simulation using the high-resolution wind (without assimilation) captures the observed spatial and seasonal patterns of the circulation, though the intensity is underestimated. With assimilation, the intensity is increased. In particular, the western-channel cyclone is reproduced well. Momentum analyses suggest that the cyclone is maintained by oppositely directed, time-dependent pressure gradients (PG) along the northern and southern coasts of the channel. These PGs are, in turn, caused by warming episodes probably related to wind relaxations. Momentum analysis also identifies along-channel PG (APG) as a dynamic index of the seasonal circulation. APG is strongly poleward in summer and autumn and becomes weak in winter. The poleward APG is eroded by equatorward wind bursts in late winter through spring during which period it changes sign to weakly equatorward. The APG becomes poleward again in early summer with the arrival of a large-scale warming signal from the Southern California Bight. The model does poorly in the eastern portion of the channel, in which region remote forcing at long periods (10-30 days) has been identified in previous observational studies. The model fails to reproduce the intense springtime (April) equatorward current $\left(\approx-0.2 \mathrm{~m} \mathrm{~s}^{-1}\right)$ at the eastern channel entrance. The corresponding variance is also underestimated. The remote forcing is not accounted for in the model because climatological conditions are specified at the open boundary in the Southern California Bight.
\end{abstract}

\section{Introduction}

Bounded by the U.S. mainland to the north and islands to the south, the Santa Barbara Channel (SBC; Fig. 1) is about $100 \mathrm{~km}$ east-west and $50 \mathrm{~km}$ northsouth, with relatively deep topography (100-500 m) except for narrow shelves $(\approx 5$-km width) north and south. Because of its orientation, westward (eastward) along

Corresponding author address: Lie-Yauw Oey, Atmospheric and Oceanic Science Program, Princeton University, Princeton, NJ 08544. E-mail: lyo@princeton.edu the channel is equivalent to poleward (equatorward), and we will freely interchange their usage when referring to currents in the channel. The SBC is a "mixing" zone between warm water of the Southern California Bight (SCB) and cooler upwelled water of the central California shelf/slope (CCSS). The strongest east-west thermal contrast, about $5^{\circ}-6^{\circ} \mathrm{C}$ near the surface, occurs during the summer at the time of peak upwelling off CCSS and warmest sea surface temperature in the SCB (Harms and Winant 1998). The region is partially sheltered from the often intense (especially in summer) north and northwesterly wind by the mountain range along 


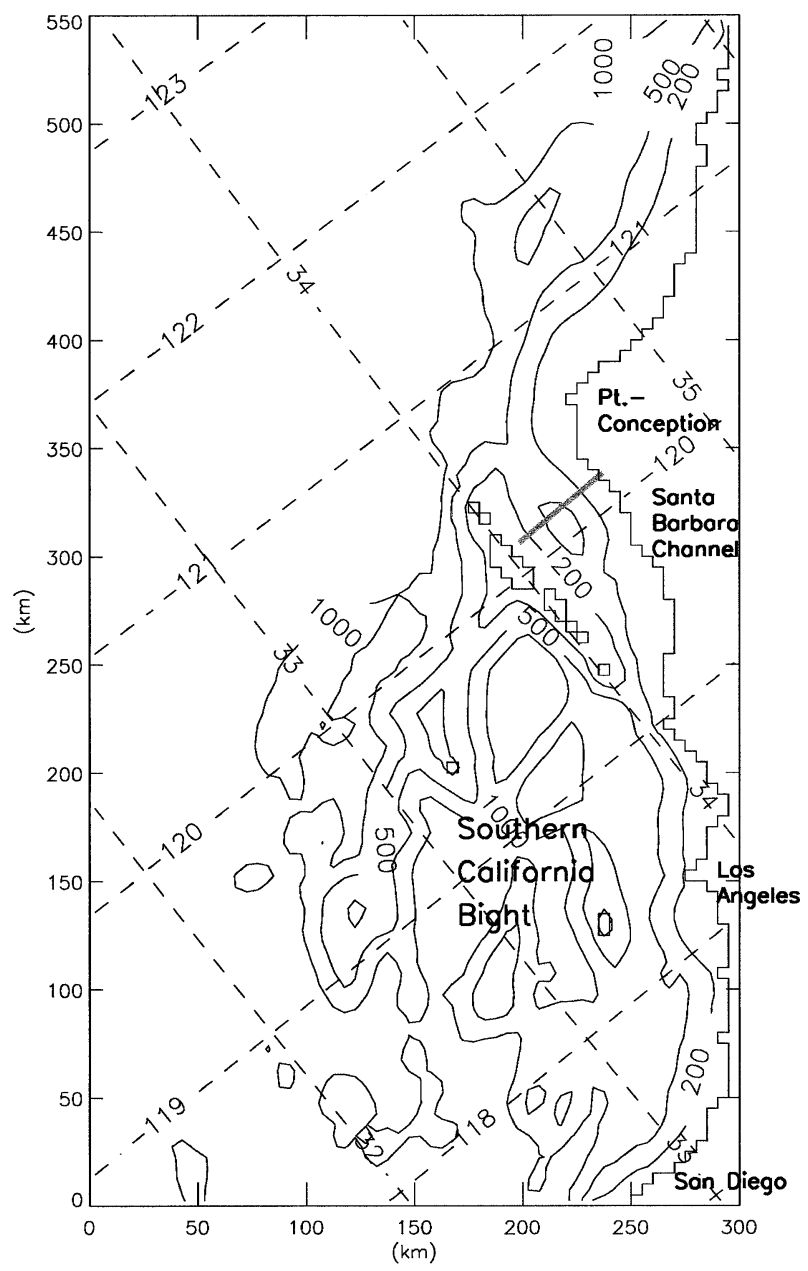

FIG. 1. Santa Barbara Channel and Southern California Bight locator map, and the model domain and topography (isobaths are in meters). For computational efficiency, the deepest model's depth has been set to $2000 \mathrm{~m}$. The thick line across the channel is where the vertical sectional contours are plotted in Figs. 9 and 13.

the channel's northern coast, and so there can be large differences in wind strengths from west (stronger) to east along the channel (Winant and Dorman 1997; Dorman and Winant 2000). The south/southeastward wind at the western entrance of the channel, for example, often exceeds $0.2-0.3 \mathrm{~N} \mathrm{~m}^{-2}$ in summer (Dorman and Winant 2000; Munchow 2000), and it decreases rapidly eastward to almost zero over a distance of about $50 \mathrm{~km}$, or about one-half of the channel length. The resulting wind stress curl is often in excess of $0.2 \mathrm{~N} \mathrm{~m}^{-2}$ (100 $\mathrm{km})^{-1}$, almost an order of magnitude larger than the typical wind stress curl values found farther offshore over the California Current (Hickey 1979). The winds also tend to be strongest at the channel's midaxis and weaker north and south near the coasts. Given these complex patterns of wind and wind stress curl and the along-channel thermal contrast, one expects equally complex circulation, at least near the surface. Moreover, the channel is within the coastal waveguide, and remote forcing affects currents in the channel.

Since 1993, the U.S. Minerals Management Service (MMS) has sponsored a field program to study the nearsurface circulation in the channel. The main objective is to collect the necessary information so that one can estimate the time-dependent near-surface current field and assess fates of surface-trapped pollutants. The period we focus on in this study is 1994. The measurements include current moorings at eight stations inside the channel, one station (PAIN) north of the channel in the CCSS, and one station (BARB) off Los Angeles, California, in the SCB (for station names and locations, see Fig. 2). Wind measurements were also acquired at the six National Data Buoy Center (NDBC) stations shown in Fig. 2. In addition, 16 coastal, island, and oilplatform wind stations were also available (Dorman and Winant 2000). For detailed descriptions of these and other measurements and observed circulation patterns, the reader is referred to Harms and Winant (1998), Auad and Hendershott (1997), Winant and Dorman (1997), Dever et al. (1998), and Dorman and Winant (2000). The MMS-sponsored research also includes a modeling component. One objective is to identify forcings that drive the major features of the near-surface circulation. We have identified that both large- $(\sim 500 \mathrm{~km})$ and small-scale $(\sim 50 \mathrm{~km})$ component winds and wind stress curls drive the observed poleward (i.e., against wind) near-coast currents in the SCB and SBC and that they also appear to be responsible for establishing the cyclone in the western portion of the channel (Oey 1996, 1999, 2000; Wang 1997; Oey et al. 2001). Second, we also developed data-assimilation procedures for hindcasting. The results show that the observed mean currents inside the channel can be reproduced (Chen and Wang 1999, 2000; henceforth CW99 and CW00, respectively).

CW99 and CW00 focused entirely on the channel region, and the open-boundary conditions and winds outside the channel are ad hoc. This paper combines Oey et al.'s (2001) large-scale model with the local model of CW99 and CW00. We extend Chen and Wang's work to simulate currents inside and outside of the channel using observed data and a more detailed wind field that includes also Dorman and Winant's (2000) 16 coastal, island, and oil-platform stations. We apply the CW99 assimilation scheme in the vicinity of the channel and make use of observed temperature and salinity climatological data in the far field to simulate currents. We compare the simulated currents in the monthly and also the synoptic wind-driven time scales (i.e., days), with and without assimilation, with those observed. By experimenting with different wind fields, we study effects of finescale $(20-50 \mathrm{~km})$ wind structures in driving the coastal circulation. A momentum analysis is used to delineate the seasonal dynamics and to explain why assimilating temperatures can better reproduce the observed currents. 


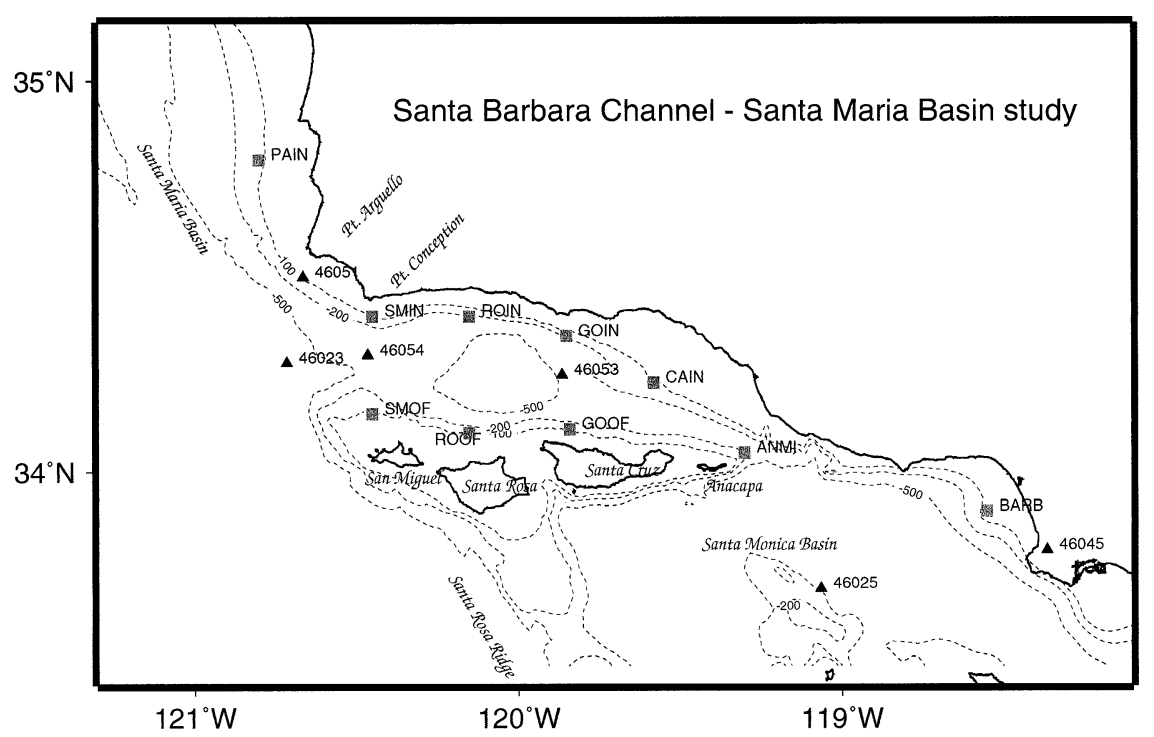

FIG. 2. Detailed locator map of the SBC region showing current-meter moorings (squares) and NDBC wind stations (triangles). Isobaths are in meters.

Section 2 describes the model, observations, assimilation scheme, and various model experiments. Section 3 presents the results and comparison with moored currents. Section 4 discusses dynamics in terms of momentum balance. The paper ends with conclusions in section 5 .

\section{Methods}

Our ocean model (the Princeton Ocean Model; Mellor $1993)$ solves the three-dimensional structure and temporal evolution of currents, temperature, and salinity. The ocean is assumed to be incompressible and hydrostatic, and Boussinesq approximation is used (details in Oey and Chen 1992, hereinafter referred to as OC92). The model domain and topography are the same as those used in Oey (1996; Fig. 1), except that the present application employs the coarse grid only (i.e., the nestedgrid option is turned off), with grid sizes $\Delta x=\Delta y=$ $5 \mathrm{~km}$ and 30 equally spaced sigma layers in the vertical direction.

\section{a. Wind forcing}

Figure 3 shows the 1994 time series of the (major) principal-axis wind stress at the six NDBC stations. We use Large and Pond's (1981) formula to compute wind stresses. Panels are arranged from north (46051; top) to south and east, and the principal-axis angle (degrees anticlockwise from east-west) is displayed on each panel. Negative wind stress values indicate equatorward (southeastward and/or eastward) winds, and these winds generally dominate except for episodic reversals, especially in winter and early spring. The principal angles generally increase from north and west to south and east. The wind veers from being southeastward north and west of the channel (buoys 46051 and 46023) to east/southeastward just inside the channel (46054) and then to almost due eastward at the eastern and southeastern stations (46053 and 46045) (Dorman and Winant 2000). Wind is strong in the west (buoys 46054, 46023 and 46051) and weak in the east and south (46053, 46025 and 46045), especially in late spring through summer. These NDBC winds and the other 16 wind data points from land, island, and platform stations provide descriptions of the finescale wind structures in the vicinity of the channel. To use these synoptic (hourly) data in the model, we "merge" them with six-hourly European Centre for Medium-Range Weather Forecasts (ECMWF) wind (resolution is approximately $1^{\circ} \times 1^{\circ}$ ) by optimally interpolating (OI; Bretherton et al. 1976) the composite data onto the model grid. The final products are hourly wind maps that include detailed wind station values in the SBC vicinity and larger-scale ECMWF information farther away.

\section{b. Data assimilation}

We briefly describe here the procedures; details are given in CW99 and CW00. Temperatures (only) at 10 moorings in the SBC are used (Fig. 2). The hourly observations contain some gaps in time. We first optimally interpolate in space every hour and use the OI values to fill the gaps. Then at each model grid $k$, the modeled temperature $T_{m, k}$ is replaced by an analyzed (or assimilated) temperature $T_{a, k}$ (Daley 1993):

$$
T_{a, k}=T_{m, k}+\sum_{i} A_{k i}\left(T_{o, i}-T_{m, i}\right)
$$

where the summation $\Sigma_{i}$ is over the 10 mooring stations 
1994 Daily Mean (46051_940i5.0.ss)

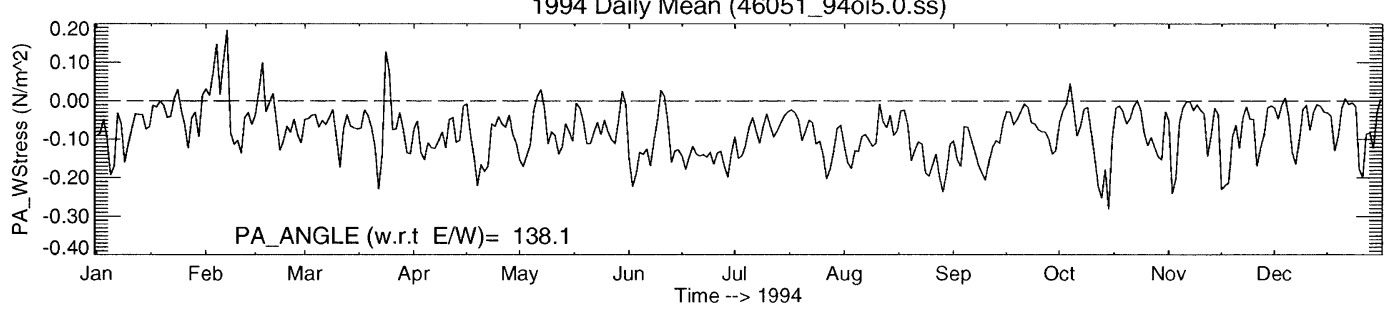

1994 Daily Mean (46023_94oi5.0.ss)

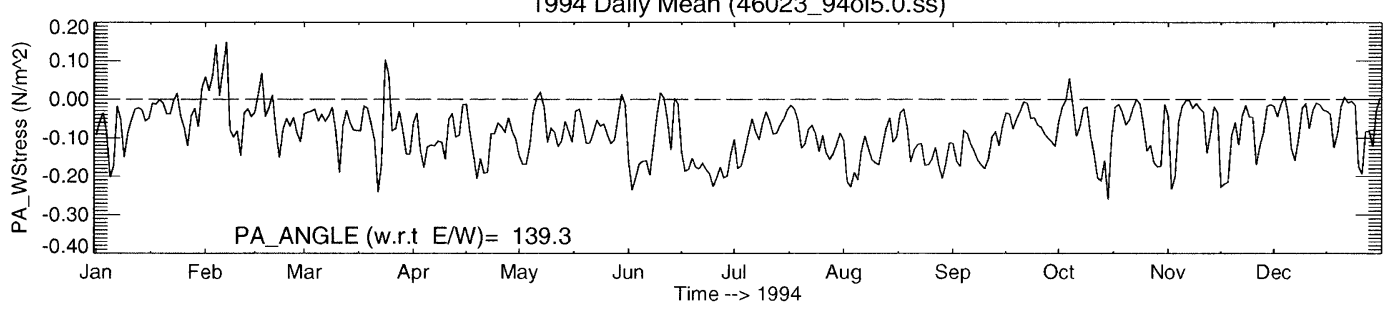

1994 Daily Mean (46054_940i5.0.ss)

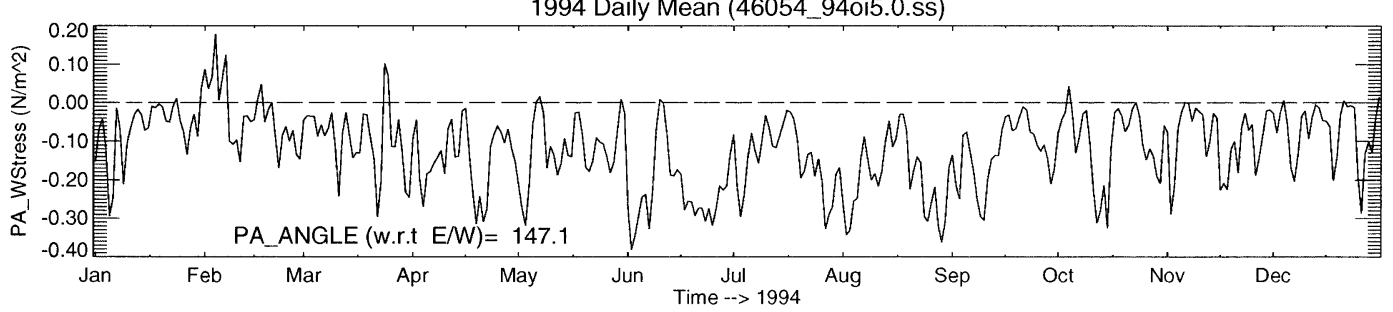

1994 Daily Mean (46053_94oi5.0.ss)

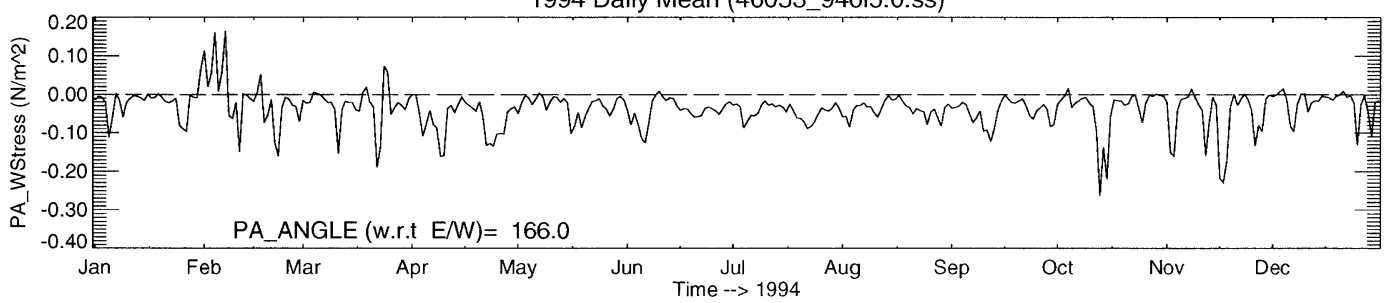

1994 Daily Mean (46025 94oi5.0.ss)

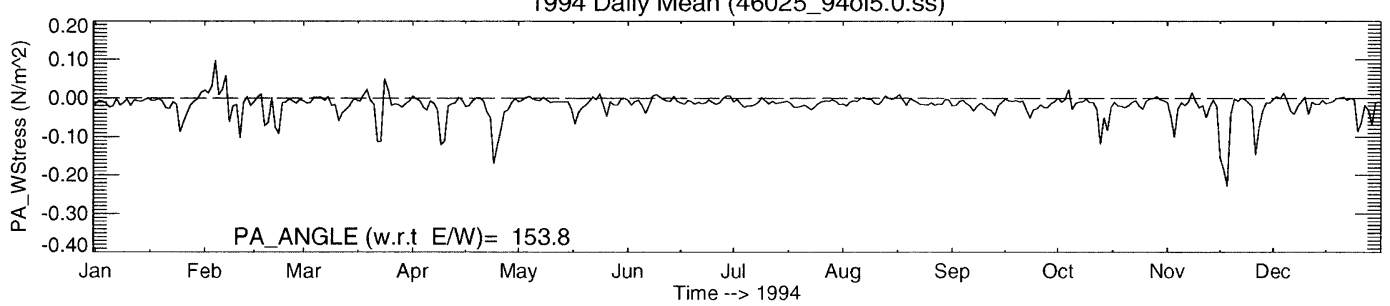

1994 Daily Mean (46045_94oi5.0.ss)

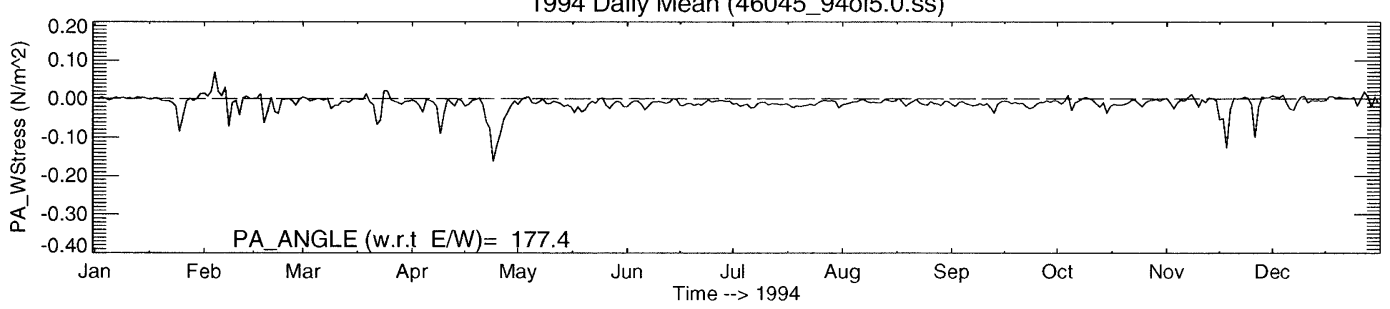

FIG. 3. Examples of the wind stress time series used in the model. Shown here are daily averaged principal-axis values at the six NDBC stations arranged from (top) north to (bottom) south: 46051, 46023, 46054, 46053, 46025, and 46045. The principal-axis angles measured in degrees anticlockwise from true east are printed on each panel. 
$i=1, \ldots, 10, T_{o, i}$ is the observed temperature at mooring $i$, and $A_{k i}$ is a predetermined statistical weighting coefficient matrix given by

$$
A_{k i}=\alpha_{k i} /\left(\sum_{i} \alpha_{k i}+\varepsilon^{2}\right) .
$$

Here, $\varepsilon^{2}=($ error variance $) /($ variance $)$ of the observation, taken as 0.1 in this paper, and $\alpha_{k i}$ is a function of the separation distance $R_{k-i}$ between the model grid $k$ and mooring station $i$, given by

$$
\alpha_{k i}=\exp \left[-\left(R_{k-i} / R_{e}\right)^{2}\right]
$$

where the error correlation scale $R_{e}$ is taken to be 10 $\mathrm{km}$. This small value of $R_{e}$ confines the injection of the observed temperature information to the immediate vicinity of the mooring. Unlike the commonly used assimilation procedure based on optimal interpolation, which generally works well in the open oceans, the coastal circulation contains various anisotropic scales, and one cannot presume to know more than what is observed (at each mooring). We, in essence, let the model seek its own decorrelation scales through dynamic readjustment of the modeled currents, which then would become consistent with the observed pressure (temperature) field.

\section{c. Initial and boundary conditions and model integration}

We use monthly temperature-salinity $(T / S)$ climatological data (Levitus 1982, 1994) to specify initial and open-boundary conditions. The open-boundary conditions are a mix of advections, radiations, and specifications as described in Oey (1996) and OC92. However, in the present year-long integration, it is necessary that a sponge layer (200 km wide), within which the horizontal viscosity is linearly increased to 10 times its interior value, is placed along the western open boundary. In combination with a radiation condition on velocities, the sponge damped westward-propagating Rossby waves and prevented the development of an artificial boundary current.

At the coast, the normal fluxes are nil, and a no-slip condition is imposed on the tangential velocity component. At the sea surface, wind stresses are specified and $T / S$ are relaxed to their monthly climatological sea surface values (OC92). At the seafloor, all normal fluxes are nil, and a quadratic bottom stress formula with a drag coefficient $=2.5 \times 10^{-3}$ is used that uses the velocity at the lowest grid (OC92).

The model was first run for 15 days in a diagnostic mode with the $T / S$ fields fixed at their January values and radiation on the velocities along the open boundaries (OC92), during which time the (initially zero) modeled currents adjust to the specified $T / S$. These $T / S$ and (geostrophically) balanced velocity fields are then taken as initial conditions, and integration contin- ues through 11 January 1995 with and without data assimilation and with and without various wind structures (next section). Along open boundaries, the monthly climatological values are then used to specify the $T / S$ profiles when there are inflows into the modeled region. When there are outflows, one-sided advection is used for the T/S fields (OC92; see also Oey 1996).

The near-surface circulation adjusts rapidly to assimilated temperature in the channel's vicinity, and the solution there is not sensitive to the use of monthly climatological $T / S$ as initial and boundary conditions. CW99 and CW00 took advantage of this fact and were able to simulate currents inside the channel even though their outer $T / S$ and other conditions were imprecise. Though this paper also focuses on the circulation in the channel (where observations are), estimates of currents that affect movements of surface particles outside the channel will also be of interest in future studies. Moreover, interpretations of dynamics within the channel require unambiguous prescriptions of outer conditions. These considerations justify the more careful treatment of outer conditions given here. On the other hand, openboundary climatological values simulate the slow seasonal cycle. The implication at the southern transect in particular is that effects from potentially energetic remote forcing are not addressed. For example, Hickey et al. (2003) found evidence of remotely forced alongshore pressure gradient signals from farther south in the SCB and off Baja California. One way to overcome this would be to assimilate data (satellite and/or $T / S$ measurements) near the southern transect (e.g., Oey et al. 2001), a procedure we hope to implement in a future model.

\section{Model experiments}

The different experiments are summarized in Table 1. Experiment A includes all wind stations and assimilation. It is described first, followed by other experiments that alter or eliminate one or more forcings and/ or specifications. Unless otherwise stated, all variables have been low-pass filtered to remove inertial oscillations prior to any analyses.

\section{a. Experiment $A$}

Figure 4 compares variance ellipses at $5 \mathrm{~m}$ for experiment A (right panel) with those computed from observations at the 10 moorings. Mean currents are shown as arrows at each station. The model reproduces the cyclonic circulation indicated by the seven moorings inside the channel, and inflow (poleward) at the eastern station ANMI, though here the modeled mean and variance ellipse are more aligned with the local isobath. At the two outer stations, PAIN (north) and BARB (south), the mean currents are equatorward and ellipses are aligned along local isobaths, in general agreement with those observed. In general, circulation models under- 
TABLE 1. Model experiments: a check mark or description means that the item was applied in the model for the specified experiment.

\begin{tabular}{|c|c|c|c|c|c|}
\hline \multirow[b]{2}{*}{ Expt } & \multicolumn{3}{|c|}{ Wind type } & \multirow{2}{*}{$\begin{array}{l}\text { Assimilation at } \\
\text { all } 10 \text { moorings }\end{array}$} & \multirow{2}{*}{$\begin{array}{l}\text { Outside } T / S \text { monthly- } \\
\text { mean climatological } \\
\text { conditions }\end{array}$} \\
\hline & ECMWF & NDBC & Island/land & & \\
\hline A & $\checkmark$ & $\checkmark$ & $\checkmark$ & J & $\checkmark$ \\
\hline B & V & $\sqrt{ }$ & J & & $\sqrt{ }$ \\
\hline $\mathrm{C}$ & $\checkmark$ & $\sqrt{ }$ & & & $\checkmark$ \\
\hline $\mathrm{D}$ & $\gamma$ & & & & $\gamma$ \\
\hline $\mathrm{E}$ & $\sqrt{ }$ & $\sqrt{ }$ & & J & $\sqrt{ }$ \\
\hline $\mathrm{F}$ & & & & J & J \\
\hline G & $\sqrt{ }$ & $\begin{array}{l}46053 \times 1.5 \text { from } 1 \text { Jan } \\
\text { to } 15 \text { May } 1994\end{array}$ & $\sqrt{ }$ & $\sqrt{ }$ & $\sqrt{ }$ \\
\hline $\mathrm{H}$ & $\sqrt{ }$ & $\sqrt{ }$ & $\sqrt{ }$ & $\begin{array}{l}\text { No assimilation at ANMI } \\
\text { from } 1 \text { Jan to } 15 \text { May } \\
1994\end{array}$ & $\checkmark$ \\
\hline
\end{tabular}

estimate rms because of inadequate physics and/or resolution (Oey 1998). In the present case, the model shows only one-half of the observed variances at PAIN and ANMI. Variances at the other seven stations inside the channel are approximately the same as those observed, and at BARB it exceeds that observed. We will show later that the sensitivity of the model solution to detailed structures of the wind, and hence also wind stress curl, accounts in part for the discrepancies between the model and observation.

Figure 5 compares the monthly mean values of the (major) principal-axis currents at $5 \mathrm{~m}$. Except for the first month (initial transient), the modeled currents approximately follow the variations shown by observations. The currents are generally poleward (positive) with time at the northern (GOIN, ROIN, and SMIN) and eastern (ANMI and CAIN) moorings and equatorward at the southern (GOOF, ROOF, and SMOF) moorings, and also at PAIN and BARB. The results are similar to those found by CW00 using a z-level model. As in their case, the present simulation also fails to simulate the strong equatorward current observed in spring (month 4 in Fig. 5) at GOOF and especially at ANMI. Harms and Winant (1998) show that currents at ANMI
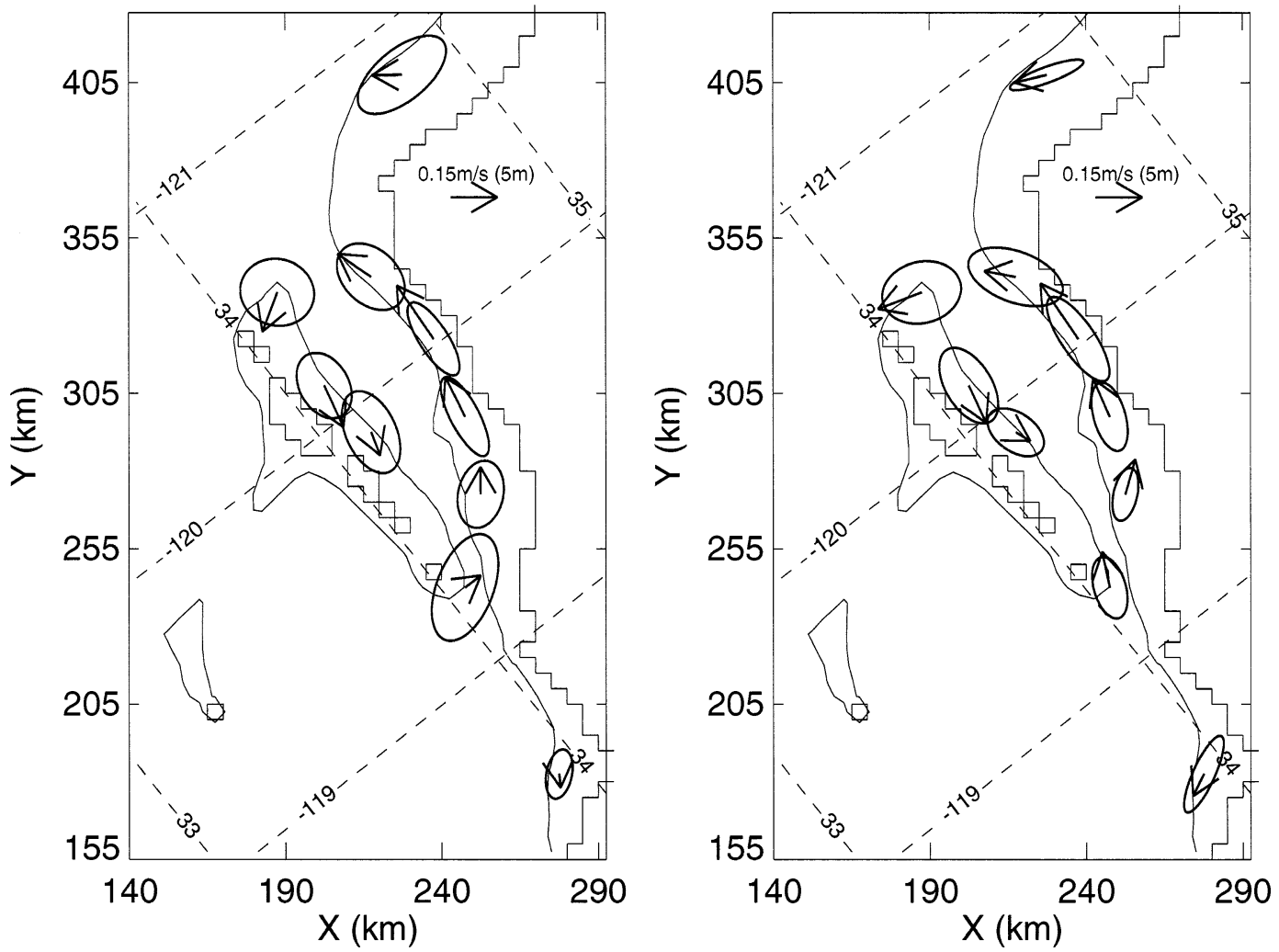

FIG. 4. A comparison of the variance ellipses at $5 \mathrm{~m}$ for (right) model expt $\mathrm{A}$ and (left) observations at the 10 current-meter moorings (see Fig. 2 for locations). Contours show the 200-m isobath. 

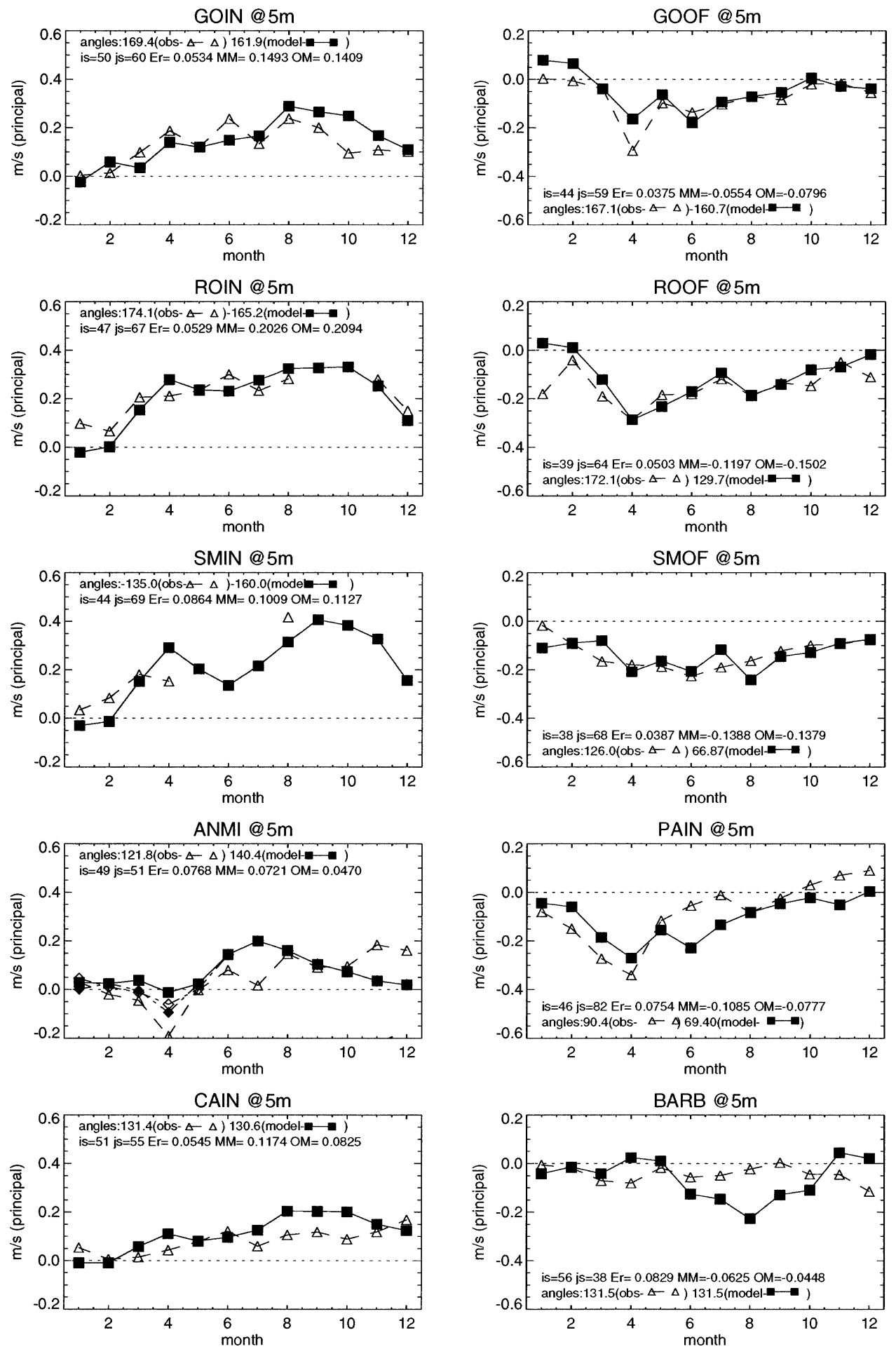

FIG. 5. A comparison of the monthly mean values of the (major) principal-axis currents at $5 \mathrm{~m}$ at all 10 moorings (Fig. 2): the solid squares indicate model expt A and the open triangles indicate the observations. In the ANMI panel, open diamonds are for model expt $\mathrm{H}$ and the solid diamonds are for expt $\mathrm{G}$. 

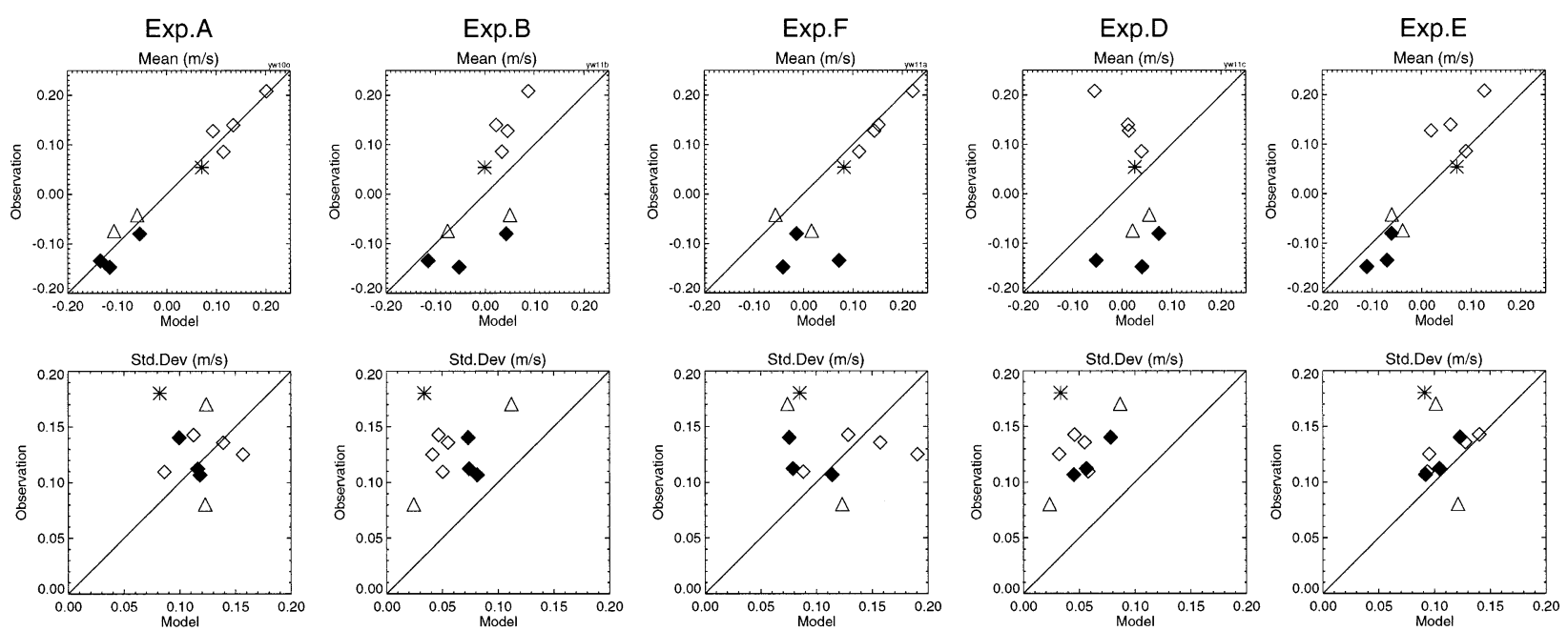

FIG. 6. The mean and standard deviation of currents for various model experiments (see Table 1) compared with observations. Triangles represent PAIN and BARB; asterisks are for ANMI; filled diamonds indicate SMOF, ROOF, and GOOF, and open diamonds show SMIN, ROIN, GOIN, and CAIN.

are in part (locally) wind driven, which the model simulates given accurate wind information. We therefore conducted two slight variants of experiment $\mathrm{A}$. The first is that in which no assimilation at ANMI was performed through 15 May 1994 (expt H, Table 1). The result shows a slightly more equatorward current at ANMI from February through April (Fig. 5, open diamond symbols on ANMI panel). In another experiment (expt G; solid diamonds in Fig. 5), the wind at buoy 46053 was increased by 1.5 times the value used in experiment A. The equatorward ANMI current in April further increases. These experiments are consistent with Harms and Winant's (1998) findings and with Oey et al's (2001) conclusion that the modeled value there is sensitive to wind over the eastern portion of the channel (i.e., near 46053).

The leftmost panels of Fig. 6 compare the mean (upper panel) and standard deviation (SD; lower panel) of currents for experiment A. As in CW2000, there is good agreement with observation for the mean values. The present simulation produces higher SD values, closer to and at some stations exceeding those observed, than those in CW2000. This is because of the smaller values of horizontal mixing used here. ${ }^{1}$

Apart from means and overall variances, we examine also how the model simulates the ocean on wind-event time scales of a few days. For this purpose, we lowpass filter both the observed and model time series to remove periods shorter than 3 days. Figure 7 shows examples of the time-series comparison at five stations: GOOF, GOIN, SMOF, ANMI, and PAIN, as well as a

\footnotetext{
${ }^{1} \mathrm{CW} 2000$ uses an eddy viscosity $=100 \mathrm{~m}^{2} \mathrm{~s}^{-1}$ (this value was not reported in CW2000); we use Smagorinsky's (1963) formulation, which gives values of about $20 \mathrm{~m}^{2} \mathrm{~s}^{-1}$.
}
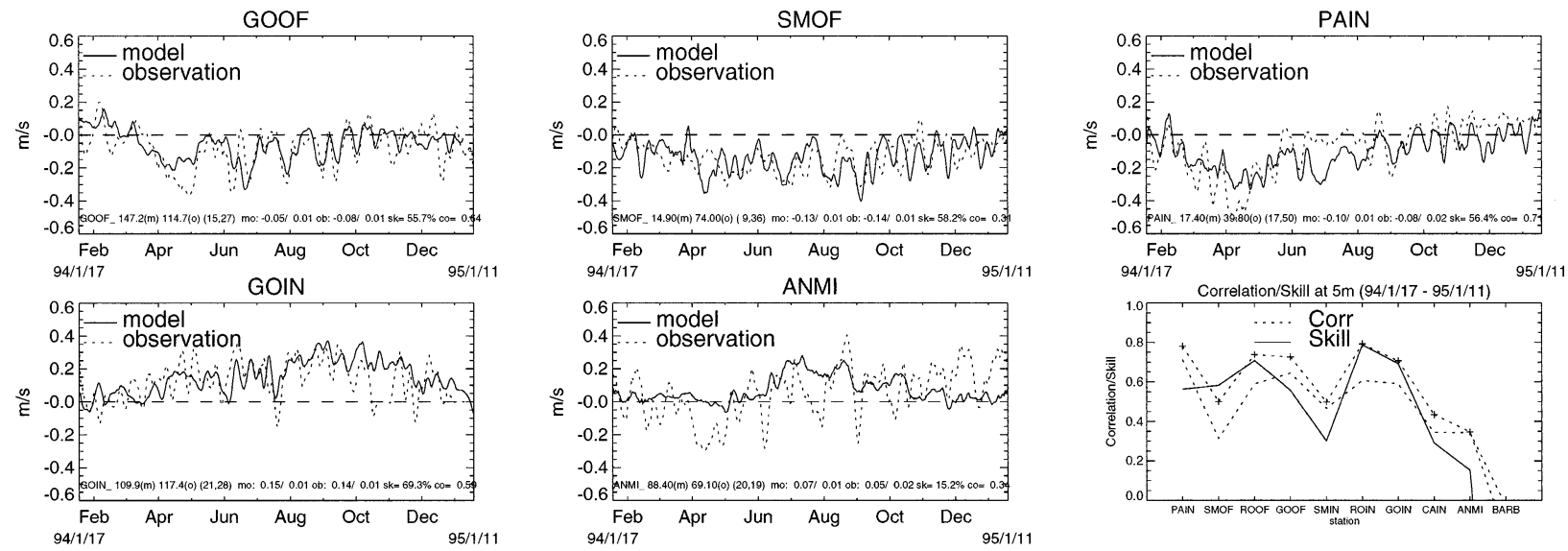

FIG. 7. Model (expt A) and observed time series at five mooring stations: GOOF, GOIN, SMOF, ANMI, and PAIN, and a (lower right) correlation and skill plot (see text) for all stations. 
(a)
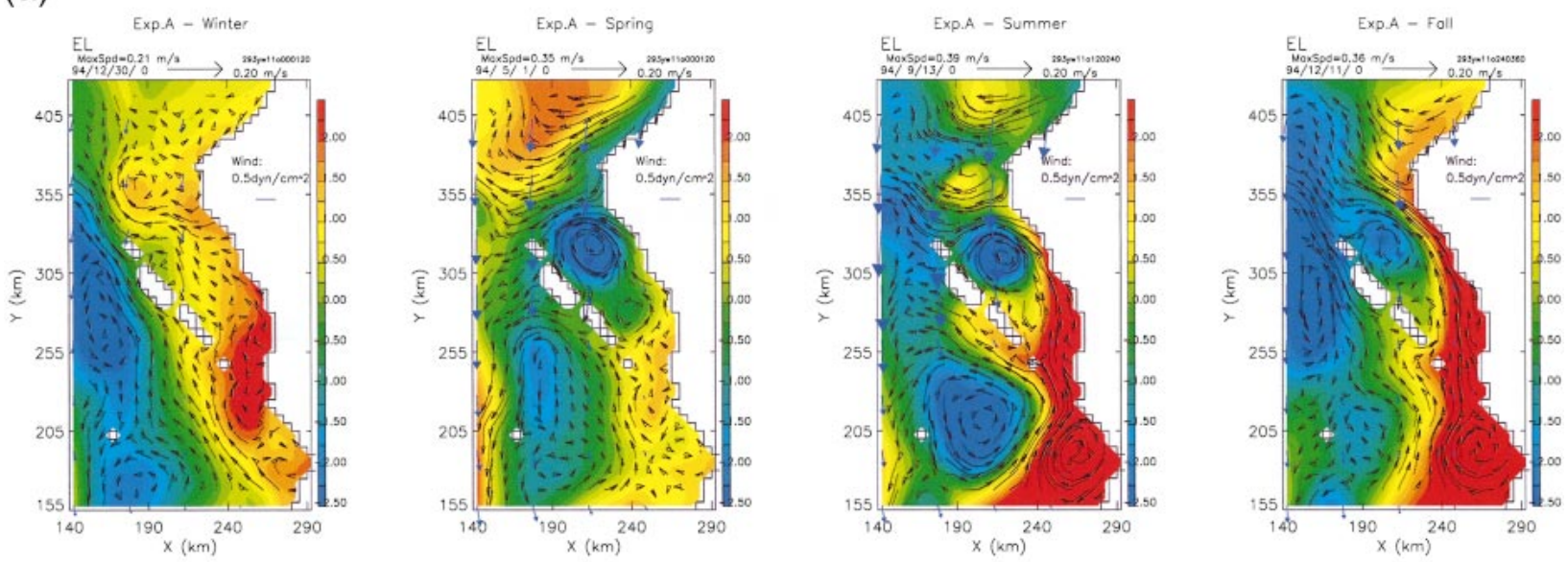

(b)
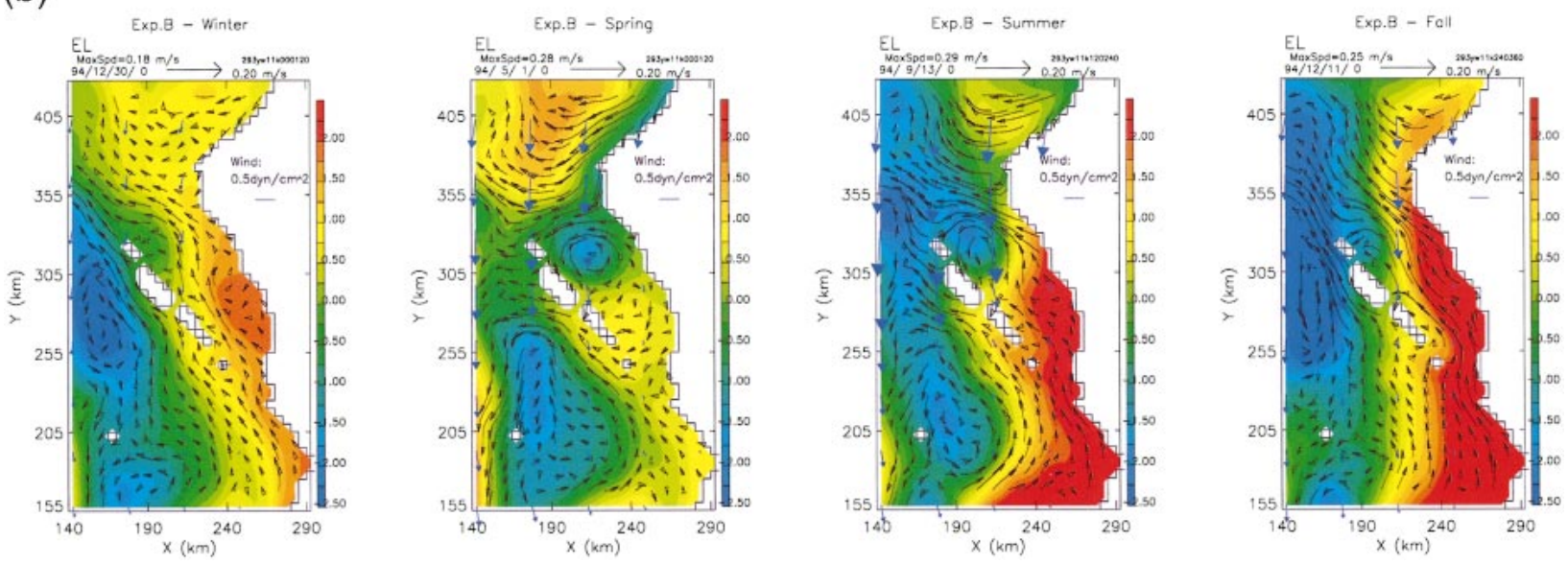

FIG. 8. The seasonal mean circulation patterns, with trajectory (defined as $\mathbf{x}=\mathbf{x}_{0}+\int \mathbf{u} d t$, where $\mathbf{x}$ and $\mathbf{u}$ are position and velocity vectors, respectively) vectors (black) superimposed on sea surface elevations, for (a) expt A and (b) expt B. Also superimposed are the corresponding seasonal mean wind stress vectors (blue vectors). These wind vectors are visible only in spring and summer and only west of the channel and over the CCSS. Time periods that define the seasons are winter: Jan-20 Feb and 15-31 Dec; spring: 21 Feb-30 Apr; summer: May-15 Sep; and autumn: 16 Sep-14 Dec.

correlation and skill (Sk) plot (lower-right panel) for all stations, where

$$
\mathrm{Sk}=\left[1-\left\langle\left(\mathbf{u}_{m}-\mathbf{u}_{o}\right) \cdot\left(\mathbf{u}_{m}-\mathbf{u}_{o}\right)\right\rangle /\left\langle\mathbf{u}_{o} \cdot \mathbf{u}_{o}\right\rangle\right]
$$

where \langle\rangle is time averaging over the entire year of 1994 , u denotes current vector, and subscripts $m$ and $o$ denote model and observation respectively (cf. Davis 1976). Values of Sk approximately equal to (but less than) 1 would, in general, indicate good agreements between model and observation.

Of the 10 stations, 5 give correlations of $\approx 0.6$ and higher $(\approx 0.7$ at PAIN), 1 gives $\approx 0.5$ at SMIN (no observation after day 100 in 1994), and the rest give low values $\approx 0.3$ or uncorrelated (BARB). With the exception of SMOF, western stations fair better than the two stations in the east, CAIN and ANMI. At ANMI, for example, though the mean is reproduced well (see Fig. 6 ), the model fails to capture 5-10-day fluctuations. The skill plot shows similar trend with generally better skills at the western stations. The dotted-plus curve in the lower-right panel of Fig. 7 gives the correlation plot when motions with periods shorter than 10 days are filtered, which gives higher correlation (and skill, not shown). Thus a portion of the model skill is due to the seasonal cycle. The results deteriorate at shorter scales and periods $[O(10 \mathrm{~km})$ and $O($ days $)]$. It is clear, however, that the model does poorly at the eastern channel (stations GOIN, CAIN, and ANMI, all year but worse in the autumn; Fig. 7) where remote forcing at longer than wind-band periods (10-30 days) has been identified in previous studies (Hickey 1992; Auad and Hendershott 1997; Hickey et al. 2003).

Figure $8 \mathrm{a}$ shows the seasonal mean circulation patterns for experiment A. Superimposed are also the corresponding seasonal mean wind stress vectors. These show weak winter currents, poleward both inside and 
(a)

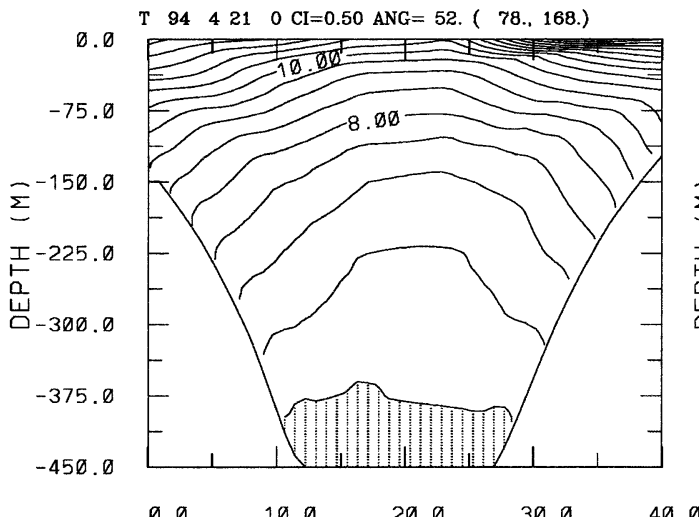

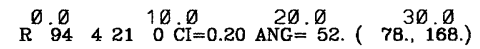

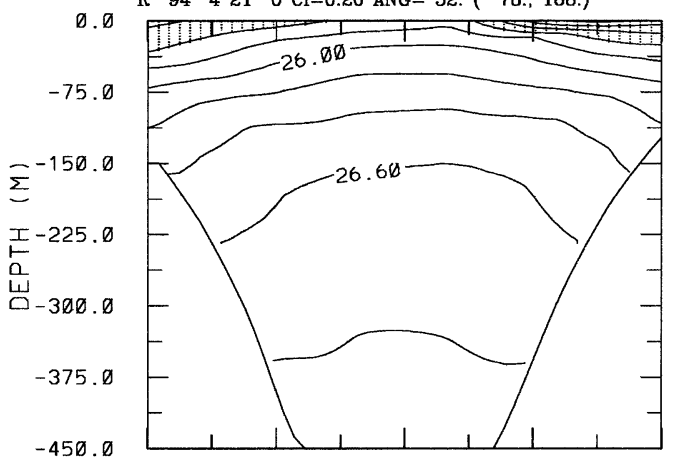

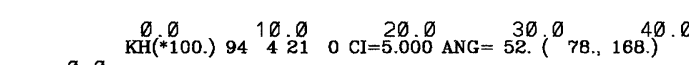

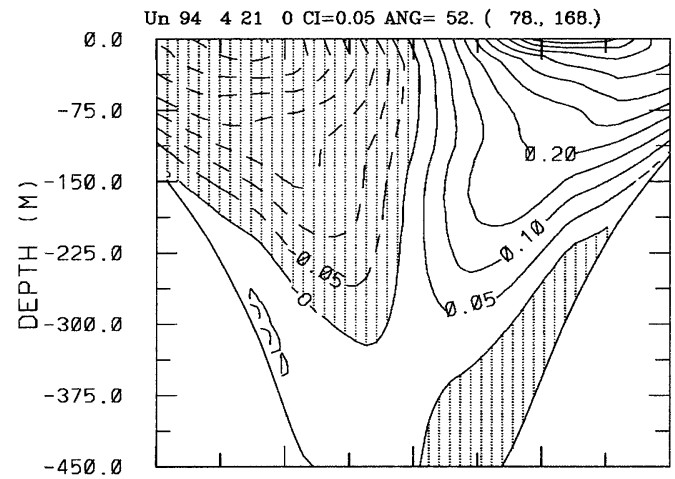

$\emptyset$

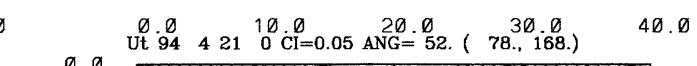

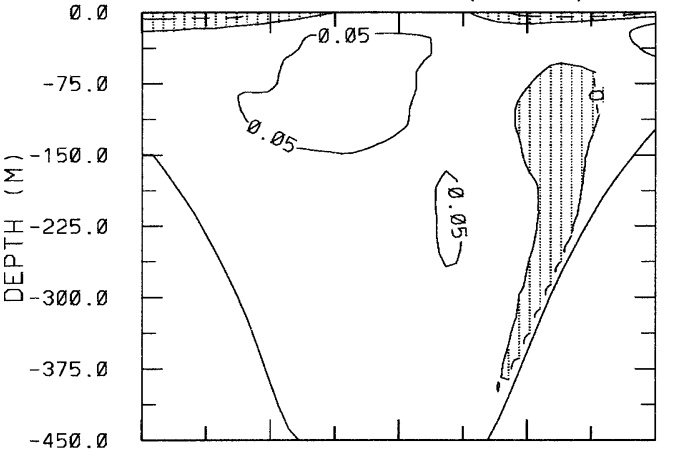
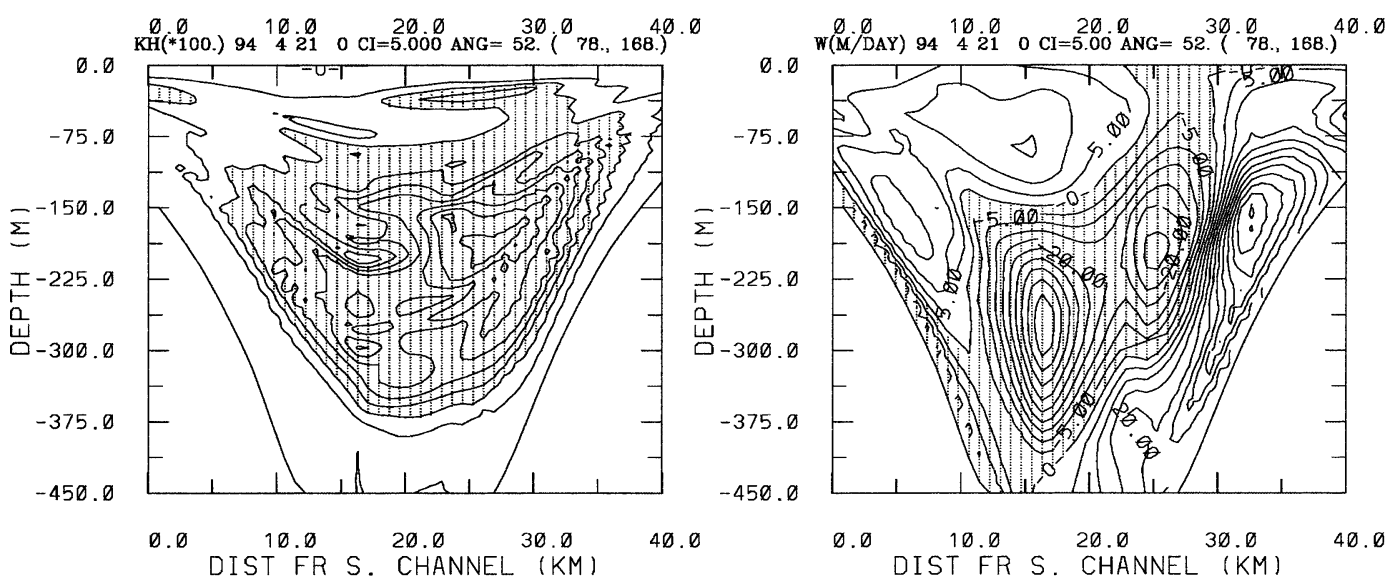

FIG. 9. Contours of flow variables in a vertical section across the channel (view toward the west) approximately passing through the cyclone center (Figs. 1 and 8a) for (a) expt A and (b) expt B. (left from top to bottom) Temperature $\left({ }^{\circ} \mathrm{C}\right)$, density $\left(\mathrm{kg} \mathrm{m}^{-3}\right.$; stippled: $\left.<25.6\right)$, vertical eddy diffusivity $\left(10^{-2} \mathrm{~m}^{2} \mathrm{~s}^{-1}\right)$; (right from top to bottom) velocity normal to section ( $\mathrm{m} \mathrm{s}^{-1}$; negative stippled: out of page, i.e., equatorward), velocity tangential to section ( $\mathrm{m} \mathrm{s}^{-1}$; negative stippled: to the left, i.e., from north to south across the channel), and vertical velocity ( $\mathrm{m} \mathrm{day}^{-1}$; negative: stippled). Note that the contour intervals for eddy diffusivity and vertical velocity are $10^{-2} \mathrm{~m}^{2} \mathrm{~s}^{-1}$ and $1 \mathrm{~m} \mathrm{day}^{-1}$, respectively, for expt B and are 5 times as large for expt A.

outside the channel. Spring and summer are characterized by strong equatorward wind over the western portion of the channel. The difference is that in spring there are more frequent equatorward winds over the eastern portion of the channel than in summer when the winds there are weak (Fig. 3; buoys 46053, 46025, and 46045). The spring forcing thus favors equatorward currents off the CCSS, the upwelling jet, and also localized cyclonic circulation over the western channel. In summer and autumn, an alongshore pressure gradient is set up by alongshore differential wind curl, which forces a poleward inflow through the eastern entrance, and the equatorward coastal currents off CCSS weaken (Oey 1996, 1999). Note the warm eddy in summer and autumn (expt 
(b)

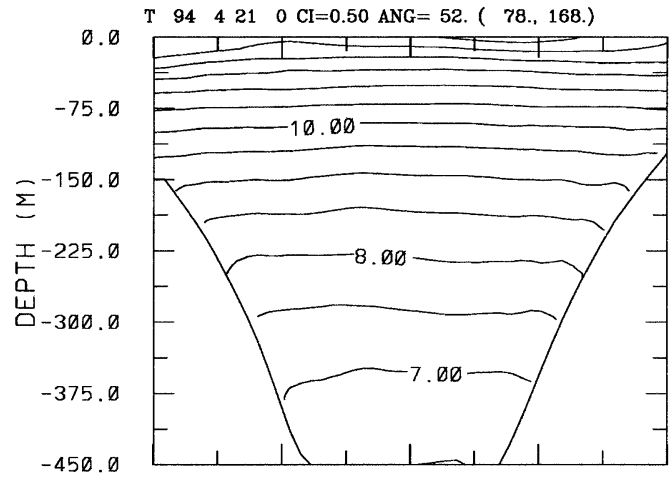

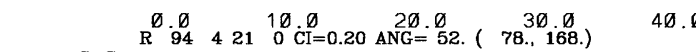

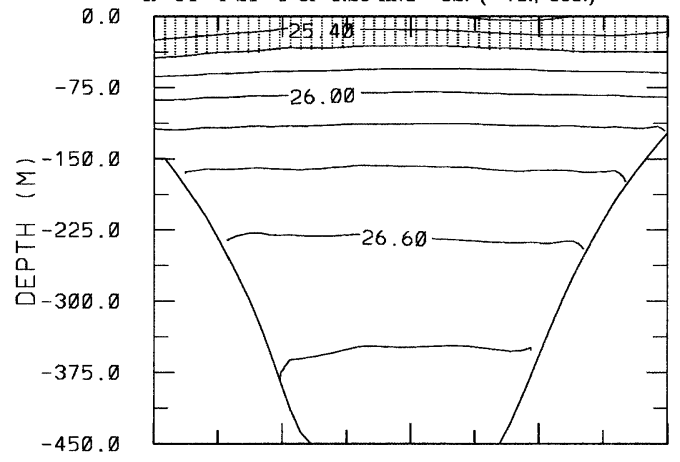

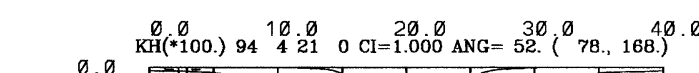

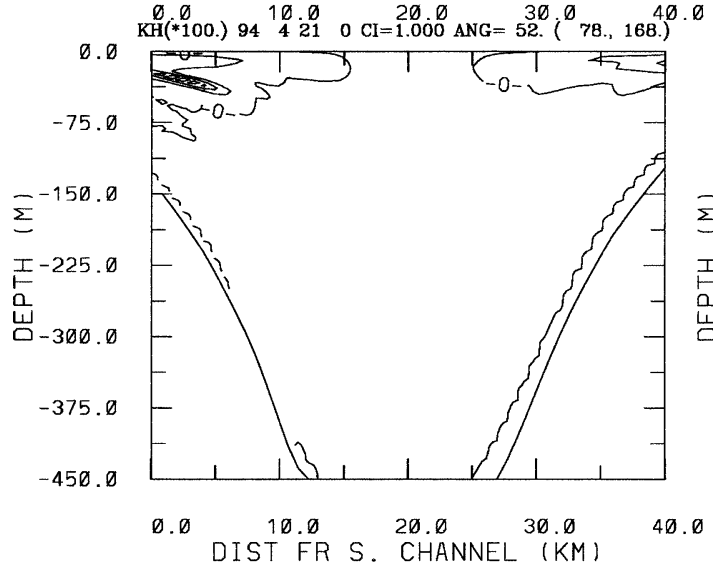

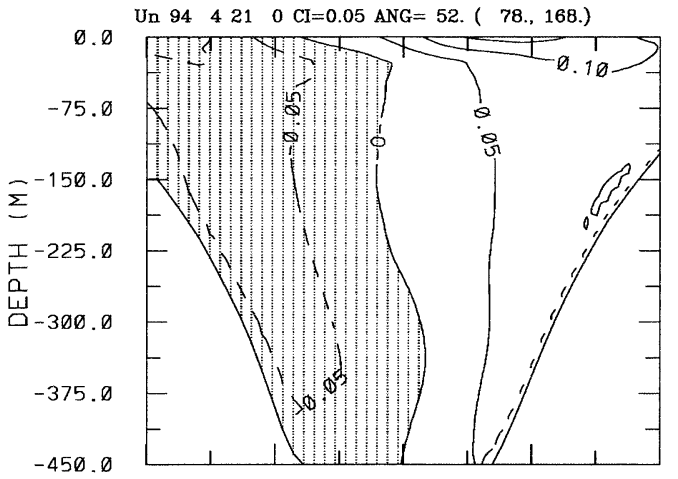

$$
0^{-45}
$$

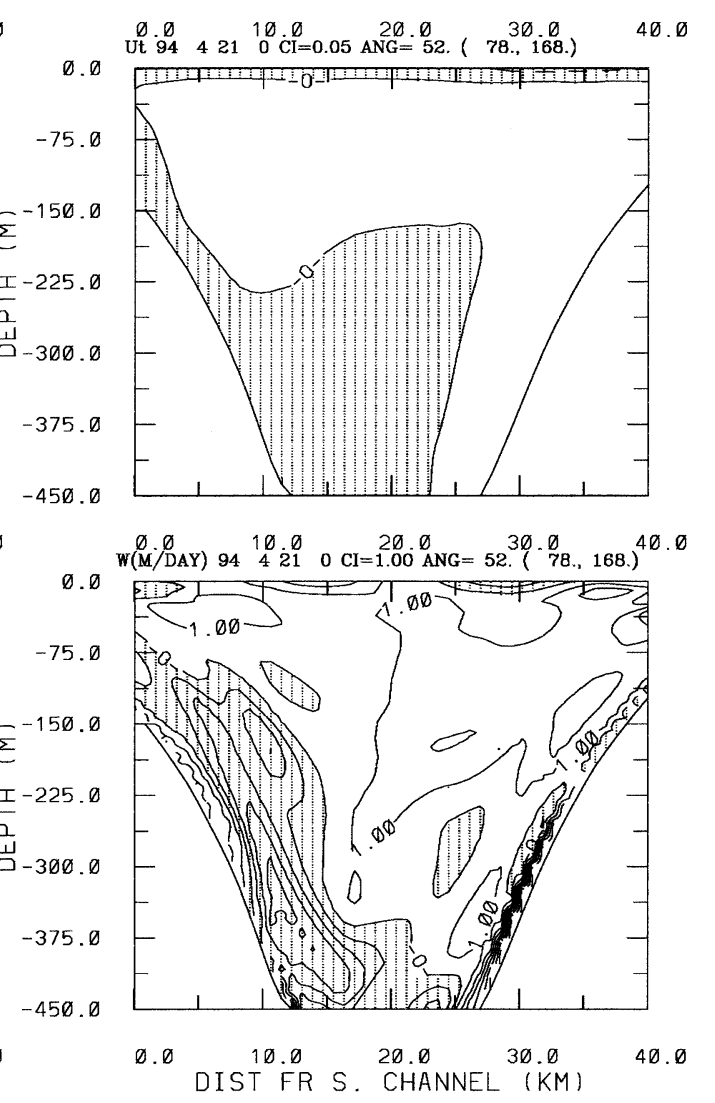

FIG. 9. (Continued)

A) in the SCB at station BARB where we assimilate temperature. The eddy is artificial but the warm water does reflect the observed conditions during that time and therefore contributes to alongshore pressure gradients. By autumn, equatorward wind and western cyclone both weaken and the circulation is predominantly poleward.

\section{b. Other experiments: Effects of wind and data assimilation}

When there is no assimilation and the wind degrades (expts B, C, and D; Table 1), Fig. 6 shows that means and SDs both become weaker. The cluster of symbols rotates counterclockwise [about $(0,0)$ ] in the mean comparison plots and shifts farther left of the $45^{\circ}$ line in the SD plots. Experiment D is worse (ECMWF only); experiment $\mathrm{C}$ (not shown) is between experiments $\mathrm{B}$ and D. Thus, detailed wind is important. Although experiment B can produce the western-channel cyclone and poleward pressure gradient (Fig. 8b), the intensities are low when compared with experiment A. Assimilation (expt A) therefore "adjusts" the pressure field so that the modeled currents correspond more closely to those observed. The stronger or cooler cyclone in experiment A is not where cooler (observed) temperature is assim- 
ilated. Rather, it is caused, through advective processes, by the adjusted pressure field resulting from temperature assimilation along the northern and southern coasts.

Experiment E illustrates the effects of removing landbased winds from experiment A, which alters the detailed distribution of wind and wind curls in the channel. The along-channel gradient of wind stress curl and the cyclone are now weakened, resulting again in counterclockwise rotation of the cluster of points for the means (especially the diamonds; see Fig. 6). Fortuitously, SDs at the three eastern stations GOIN, CAIN, and GOOF are now larger in experiment $\mathrm{E}$ (i.e., the three points move right toward the $45^{\circ}$ line). These comparisons indicate the importance of small-scale winds.

Experiment $\mathrm{F}$ with data assimilation alone but without wind shows a good depiction of the poleward currents at the four moorings along the northern channel's coast (the four open diamonds in Fig. 6). However, equatorward currents at the three southern moorings (solid diamonds) become weaker than experiment A, which suggests that currents at these locations are in part windinduced. Also, experiment $\mathrm{F}$ fails to capture (not shown) the seasonal circulation as shown in Fig. 8, which suggests that wind and wind curl play a fundamentally important role. The larger SDs when compared with the experiment without data assimilation but with the most complete wind, experiment B, suggest that density-driven fluctuations are significant.

\section{c. Vertical-section structures: Experiments $A$ and $B$}

The effect of assimilation on deeper levels is shown in Fig. 9. The figure compares contours of various flow variables at a cross-channel vertical section (shown in Fig. 1) through the cyclone center (Fig. 8). The view is westward, and positive $U_{n}\left(U_{t}\right)$, the velocity normal (tangential) to the section, is poleward (northward). The cyclone of experiment $\mathrm{A}$ is intense: $U_{n} \approx 0.5(-0.35)$ $\mathrm{m} \mathrm{s}^{-1}$ on the northern (southern) side near the surface with significant horizontal and vertical shears that extend to deep layers $z \approx-300 \mathrm{~m}$. Experiment $\mathrm{B}$ shows a weaker cyclone: $U_{n} \approx 0.15(-0.1) \mathrm{m} \mathrm{s}^{-1}$ with little shears. The vertical shears of experiment A result in vertical diffusivity $K_{H}$ that also extends to deeper layers. Turbulence is predominantly wind-stirred in experiment $\mathrm{B}$, and $K_{H}$ is confined near the surface. In experiment $\mathrm{B}$, the momentum balance near the surface is between the vertical divergence of shear stress ( $\propto$ wind stress) and the Coriolis force; thus $U_{t}$ is southward in a thin surface layer (Fig. 9b). This southward surface flow is consistent with a generally more intense and larger region of downwelling over the southern channel slope. In experiment A, there are now two surface "fronts" (see the $25.6 \sigma_{t}$ contour-separating stippled and nonstippled regions in Fig. 9a), one in the north and another weaker one in the south. There is flow convergence (divergence) at the northern (southern) front and, hence, downwelling (upwelling) of up to $-45 \mathrm{~m} \mathrm{day}^{-1}(+15$ $\mathrm{m}$ day $^{-1}$ ), which extends to deeper layers.

In summary, the model without assimilation but with detailed wind forcing (expt B) captures the general circulation inside the channel, including poleward flows in autumn and winter and development of cyclones in spring and summer (Fig. 8b). Data assimilation (expt A) increases the intensity of the circulation response so that the simulated currents agree more closely with observations (Fig. 8a).

\section{Dynamics: Force balance}

The circulation dynamics are better understood by examining the force balance. It is also useful to contrast the force balance between experiments A and B. We will first discuss experiment B for which the solution satisfies exactly the conservation equations and there are no sources and sinks due to assimilation. This is justified because the general circulations in both are similar, suggesting a common underlying dynamics. Let $x$ be the cross-shore coordinate, positive shoreward (or from the Channel Islands to mainland inside the SBC), and $y$ alongshore, positive poleward (cf. Oey et al. 2001). In the SBC, positive $x$ points roughly northward and positive $y$ points approximately westward. The $x$ and $y$ momentum equations are

$$
\begin{array}{ccc}
\mathbf{U}_{t}+\mathbf{U}_{3 \mathrm{D}} \cdot \boldsymbol{\nabla}_{3 \mathrm{D}} \mathbf{U}= & -f \mathbf{k} \times \mathbf{U}-g \boldsymbol{\nabla} \eta \\
\mathrm{I} & \mathrm{III} & \mathrm{IVa} \\
& -g \int_{z}^{0} \boldsymbol{\nabla I}\left(\rho / \rho_{o}\right) d z^{\prime} \\
& \mathrm{IVb} \\
& +\left(K_{M} \mathbf{U}_{z}\right)_{z}+\mathbf{F} . \\
& \mathrm{V} & \mathrm{VI}
\end{array}
$$

Here, $\mathbf{U}=(U, V)$ is the horizontal velocity, $\mathbf{U}_{3 \mathrm{D}}=(U$, $V, W)$ is the full three-dimensional velocity, $\mathbf{k}$ is a $z-$ directed unit vector, $\eta$ is the free-surface elevation, $\boldsymbol{\nabla}$ $=\mathbf{i} \partial / \partial x+\mathbf{j} \partial / \partial y, \nabla_{3 \mathrm{D}}=\boldsymbol{\nabla}+\mathbf{k} \partial / \partial z, K_{M}$ is the vertical eddy viscosity, $\mathbf{F}$ represents the horizontal viscous terms and a term arising from the curvature of the isobath or coastline (both in general are small), and other symbols are standard. Near the surface, the vertical shear-stress term $\mathrm{V}$ is in general dominated by $\tau^{o}$, the (kinematic) wind stress. At each model grid, these momentum terms are hourly averaged and therefore include also shortperiod (e.g., inertial) motions.

\section{a. The wind-only experiment $B$}

Figure 10 shows time series of the balance terms (with signs included) averaged inside the channel at the first sigma level near the surface for experiment B. The nonlinear advection (II) and horizontal viscous (VI) terms are small and are not plotted. The tendency term (I), on 

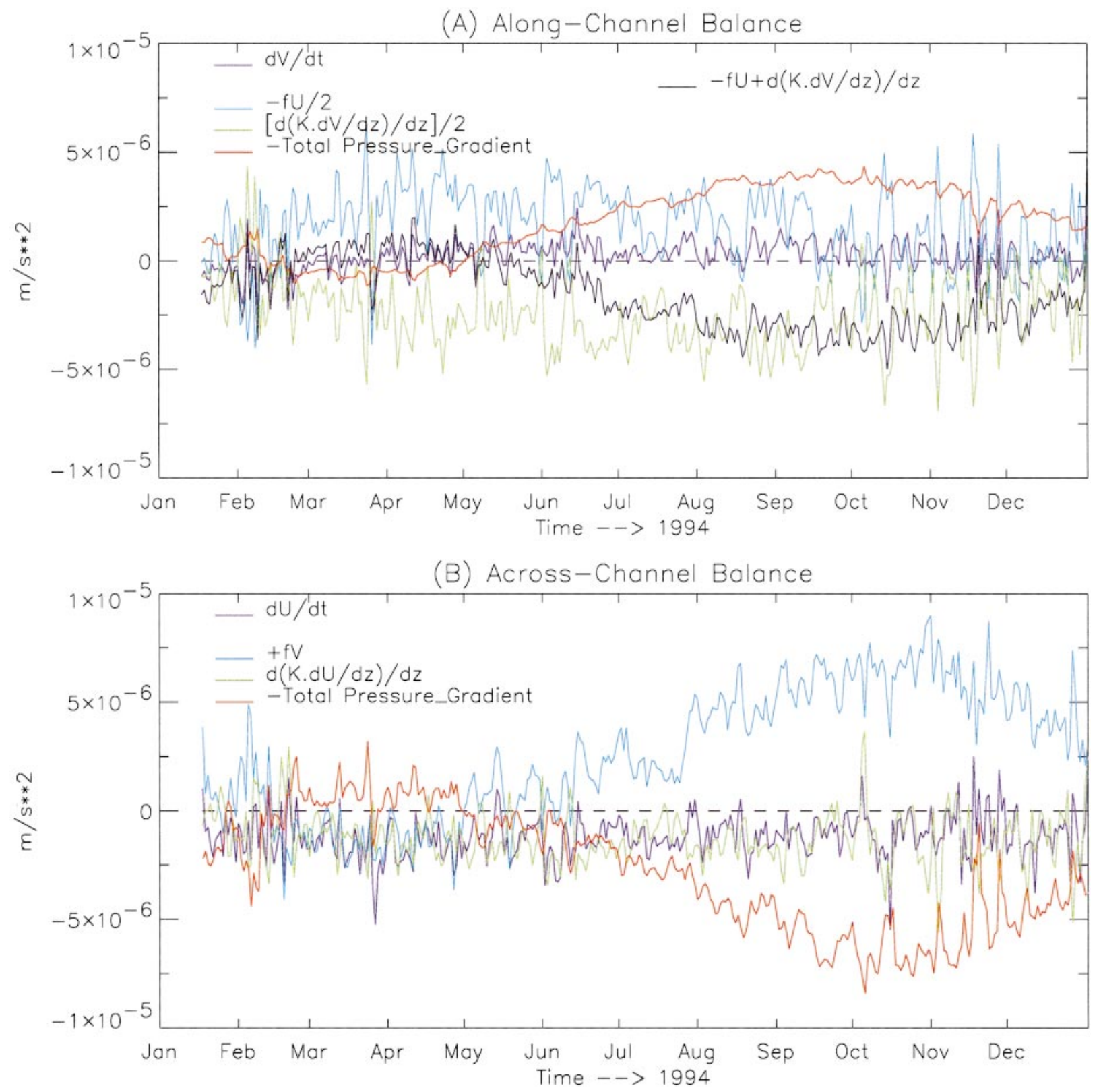

FIG. 10. Time series of the dominant momentum balance terms for expt B in (a) along-channel, positive westward (poleward) and (b) across-channel, positive northward directions. For plot clarity, the Coriolis and vertical shear terms in (a) are multiplied by 0.5. The terms are spatially averaged within the channel (see Fig. 11), and the hourly values are sampled daily for plotting.

the other hand, can be significant and represents the imbalance of the other three, generally more dominant, terms: III, IVa + IVb and V. Near the surface, term IVb is also small, and the total pressure gradient is dominated by term IVa, the sea surface slope. For depths $>200 \mathrm{~m}$, $\eta$ corresponds closely to the $0 / 200$-dbar dynamic height.

In the along-channel balance (Fig. 10a), $-f U$ (light blue) and $\left(K_{M} V_{z}\right)_{z}\left(\approx \tau^{o y}\right.$; light green) are (anti) correlated throughout the year: $\operatorname{Corr}\left[-f U,\left(K_{M} V_{z}\right)_{z}\right]=$ -0.89 , where "Corr" denotes the correlation between the indicated variables. The balance represents cross- channel Ekman current responses to the fluctuating along-channel winds. In winter through spring $(t<15$ May) when the along-channel pressure gradient (PG; red) is weaker, $-f U$ and $\left(K_{M} V_{z}\right)_{z}$ are dominant and nearly balance each other (correlation $=-0.97$ ). In winter $(t<$ March), passage of storms (Dorman and Winant 2000) produces fluctuating cross-channel Ekman fluxes $-f U$ and cross-channel $-g \eta_{x}\left[\operatorname{Corr}\left(-f U,-g \eta_{x}\right)=\right.$ $0.79]$. By geostrophy episodes of through-channel flow, $f V$ is also produced [Corr $\left.\left(f V,-g \eta_{x}\right)=-0.72\right]$. Examples of this latter correlation when the along-channel 

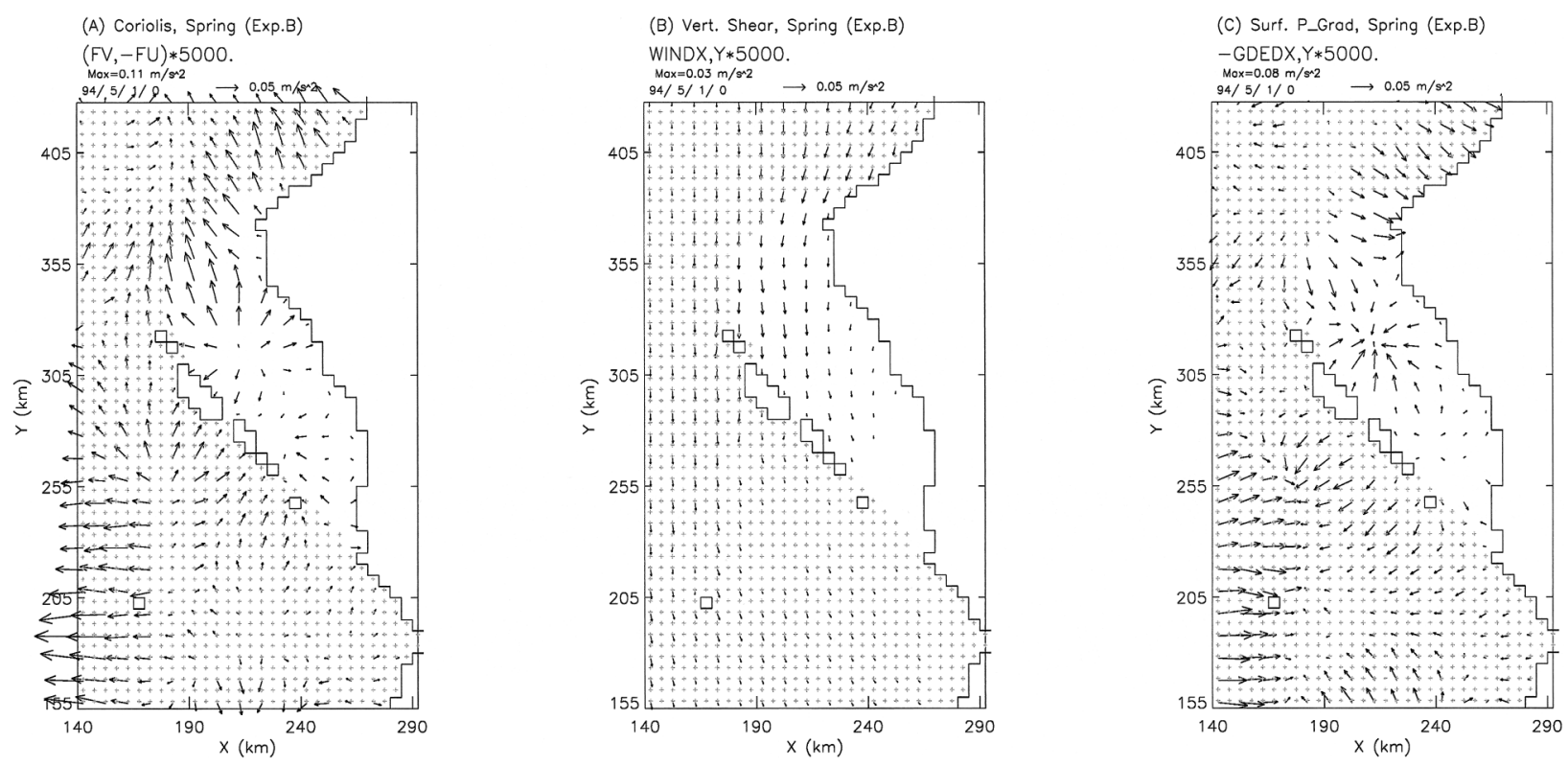

FIG. 11. Spring momentum-balance vectors calculated for expt B: (a) Coriolis, (b) vertical shear, and (c) pressure gradient. The region inside the channel for which area averages are calculated for time series plots (Figs. 10 and 12) is not stippled.

flow reverses can be seen in Fig. 10b: $f V>0$ or poleward flows on 17-23 January and 27 January-13 February and $f V<0$ or equatorward flows on 23-27 January and 13 February through spring. Such flow reversals in winter are observed (Harms and Winant 1998). In general, the links as indicated by the above force balances and correlations can be symbolically written as

$$
\begin{array}{rccc}
\tau^{o y} & \Rightarrow f U \Rightarrow g \eta_{x} \Rightarrow f V . \\
\text { Correlation: } & 0.97 & 0.79 & 0.72
\end{array}
$$

Although $f U \approx\left(K_{M} V_{z}\right)_{z}\left(\approx \tau^{o y}\right)$ and $f V$ and $g \eta_{x}$ are correlated, they, especially the latter pair, do not quite balance each other. The tendency terms [in particular, $\partial U / \partial t$ (dark blue); see Fig. 10b] have comparable magnitudes, especially in winter. That the tendency and Coriolis terms are comparable suggests that in winter inertial motions are relatively important.

In summer and autumn (16 May $<t<$ December), Corr $\left[-f U,\left(K_{M} V_{z}\right)_{z}\right]$ remains high $(-0.89)$. However, they now no longer balance each other (Fig. 10a). The increased poleward PG in summer and autumn weakens the southward cross-channel flow, and, hence, also the poleward Coriolis force. The imbalance (black in Fig. 10a) between this weakened poleward Coriolis force and the equatorward wind is an equatorward force that is almost exactly balanced by the increased poleward PG (compare black and red curves in Fig. 10a).

The PG terms indicate seasonal shift in dynamics (Fig. 10, red curves). ${ }^{2}$ Both $-g \eta_{x}$ and $-g \eta_{y}$ change

\footnotetext{
${ }^{2}$ The seasonal momentum balances may be very different from event-scale balances.
}

signs around 23 February, from generally positive $\left(-g \eta_{y}>0\right.$, or westward) and negative $\left(-g \eta_{x}<0\right.$, or southward) in winter (prior to 23 February) to negative (eastward) and positive (northward) from late winter through spring 23 February-2 May. They change signs again on 2 May, reaching maximum strengths (i.e., westward and southward, respectively) in October and then weakening in late autumn and winter. The negative/positive scenario from late winter through spring indicates (channel averaged) equatorward flow, and the positive/ negative scenario indicates poleward flow. We find that not only $\operatorname{Corr}\left(f V,-g \eta_{x}\right)=-0.72$ (as mentioned above), but also $\operatorname{Corr}\left(f V, g \eta_{y}\right)=-0.77$. Thus poleward along-channel and southward across-channel PGs correspond to poleward along-channel flows, and vice versa. The model (Fig. 8b) suggests that the spring/summer cyclonic circulation in the western channel and coastal upwelling off the CCSS are weakened in autumn and obliterated in winter. In autumn through winter, high pressure signal along the mainland coast penetrates north onto the CCSS (Fig. 8b; cf. Oey 1999). This high pressure is eroded in late winter and also with the onset of spring by a series of storms and equatorward wind bursts (starting as early as 23 February in the present study) that extend to east and south of the channel (see Fig. 3, stations 46053, 46025, and 46045). The characteristics of these springtime wind bursts are different from the equatorward winds in summer, which are primarily confined to west of the channel and over the CCSS. The first sign reversal in PG around 23 February thus reflects this incipient shift in dynamics from late winter to spring. It is conceivable that the annual ritual of the so-called spring transition, most apparent in the 

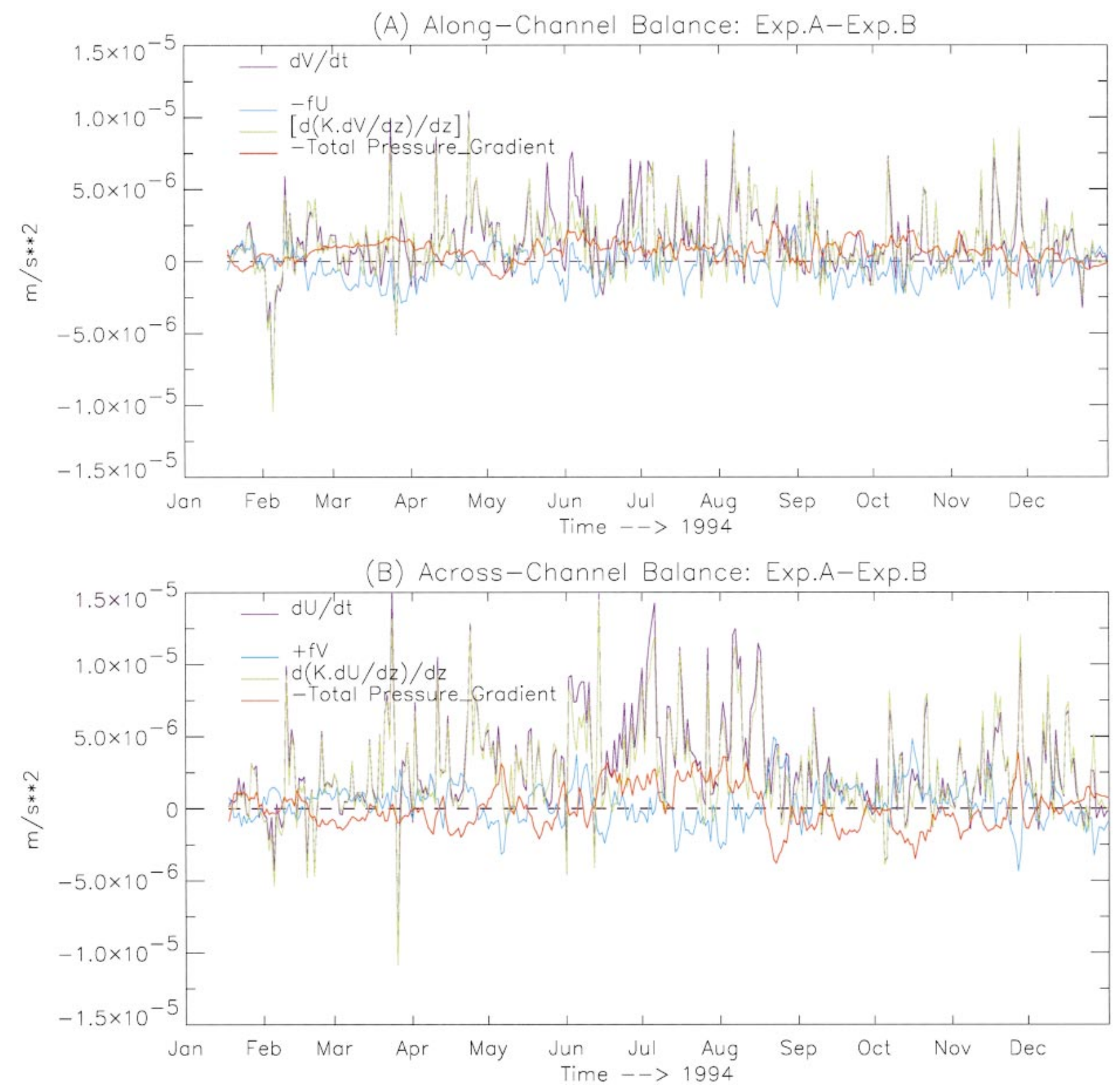

FIG. 12. Same as Fig. 10 but for balance differences, expt A - expt B.

ocean as an almost instantaneous ( $\sim 1-2$ weeks) intensification of the equatorward coastal jet off CCSS around April, may have been induced weeks or even months earlier by wind bursts and pressure erosion.

We have also examined spatial structures of the force balance in terms of maps of acceleration vectors. The more interesting finding is during spring (Fig. 11). The western cyclone is seen as convergent and divergent pressure gradient and Coriolis vectors respectively. These force vectors are balanced by the strong windinduced shear in the west. As expected, the PG in the eastern portion of the channel is very weak. Because in the model PG represents a portion of the remote signal from the Southern California Bight (Oey 1999; Hickey et al. 2003), we conclude that the western cyclone in spring is locally spun up by the wind. In other words, the weak along-channel PG in spring cannot force a cyclone through the geostrophic adjustment process of along-channel difference in density.

\section{b. Experiment $A$ (with assimilation) ${ }^{3}$}

Figure 12 shows time series of changes (i.e., expt A - expt B) in the dominant balance term(s). Data assim-

\footnotetext{
${ }^{3}$ Momentum is not balanced at the exact time step when assimilation is effected. This occurs every 1 day and was omitted from the data before processing.
} 
(a)
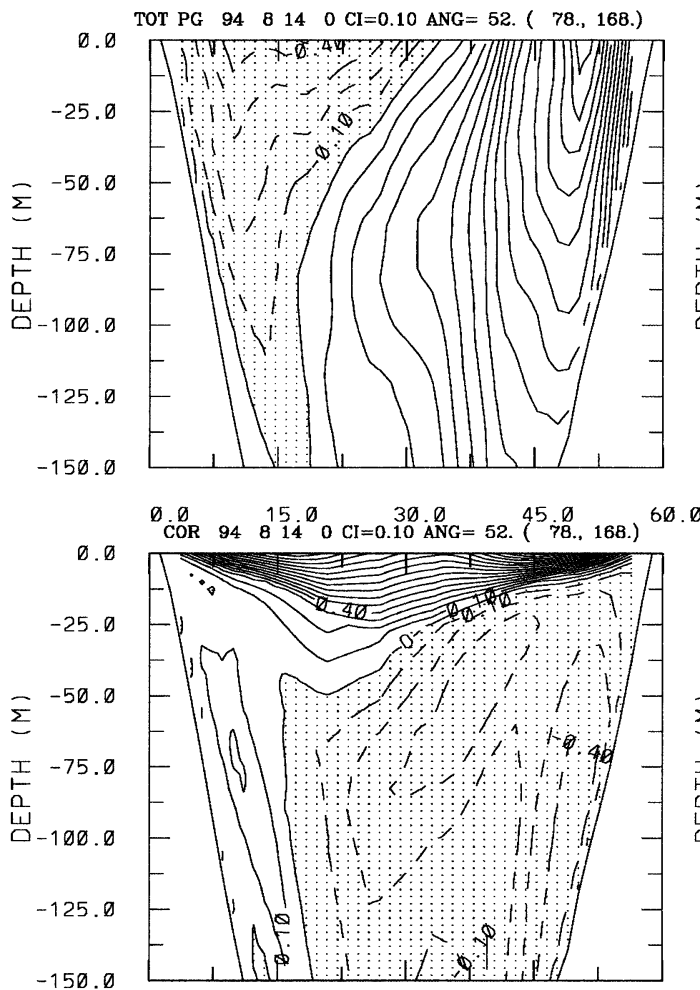

$00 \quad 150 \quad 30.0 \quad 450 \quad 60.0$

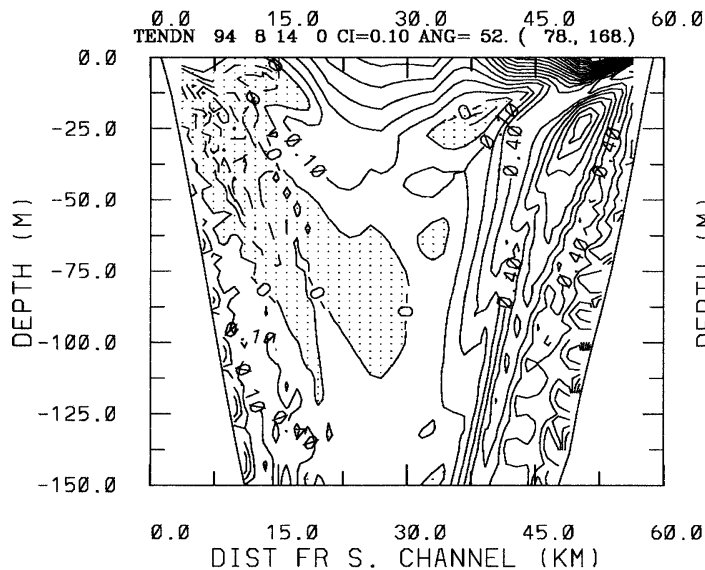

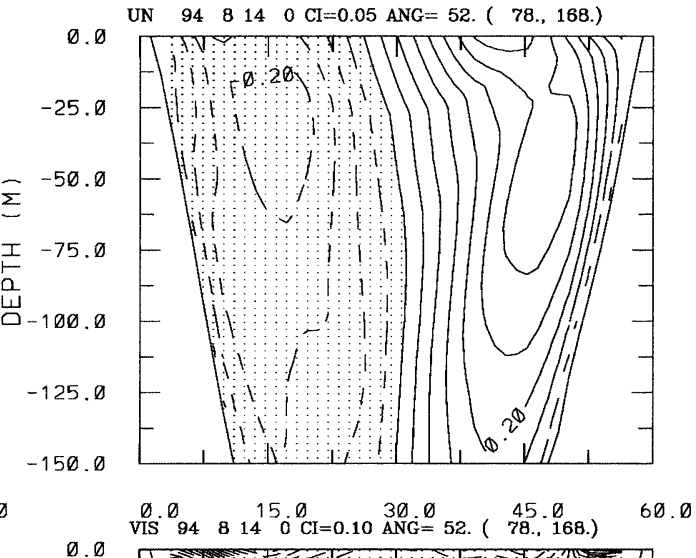
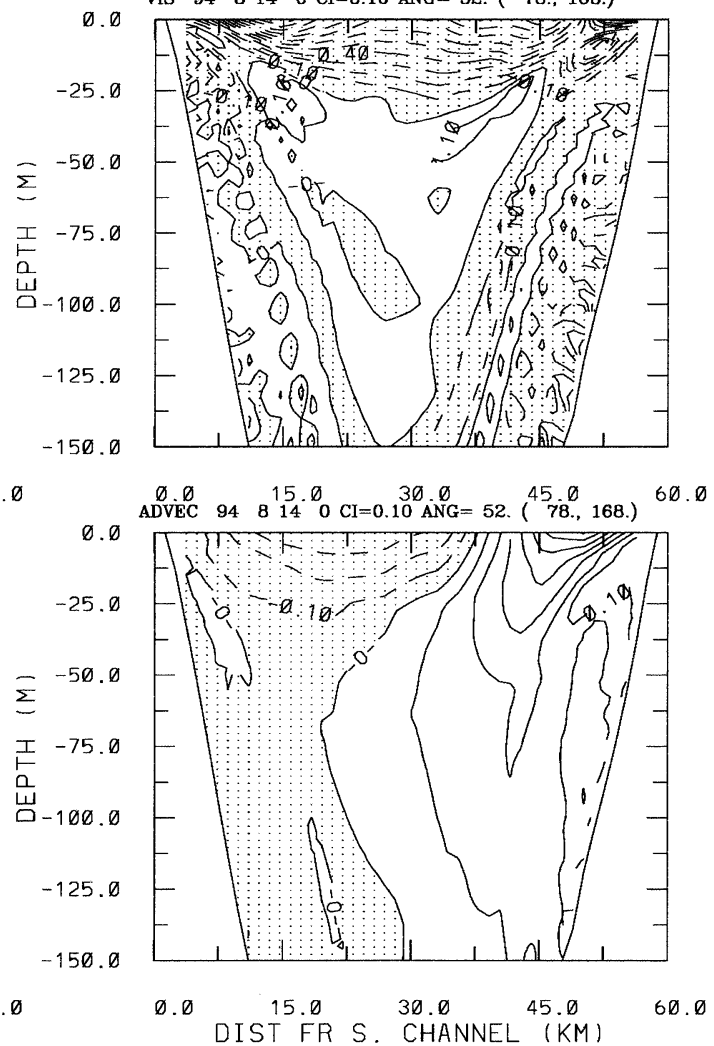

FIG. 13. Contours of along-channel momentum balance terms [contour interval $(\mathrm{CI})=0.1 \mathrm{~m} \mathrm{~s}^{-2}$ ] and velocity $(\mathrm{CI}$ $=0.05 \mathrm{~m} \mathrm{~s}^{-1}$ ) in a vertical section across the channel (view toward the west) approximately passing through the cyclone center (Figs. 1 and 8a) (positive westward or poleward, and negative values are stippled) for (a) expt A and (b) expt B for the summer. (left from top to bottom) Pressure gradient, Coriolis, tendency; (right top to bottom) velocity normal to section, vertical shear, and advection.

ilation produces approximately $50 \%$ stronger poleward $\mathrm{PG}$, that is, $\delta_{\mathrm{AB}}\left(-g \eta_{y}\right)>0\left[\delta_{\mathrm{AB}}()\right.$ denotes the difference of the variable inside the parentheses], fairly consistently through the year. The time series for the change in cross-channel $\mathrm{PG}, \delta_{\mathrm{AB}}\left(-g \eta_{x}\right)$ is more variable. The variation reflects differences in the cyclone structures between experiments $\mathrm{A}$ and $\mathrm{B}$. The Coriolis and $\mathrm{PG}$ are well correlated with little lag, $\operatorname{Corr}\left(-g \eta_{y},-f U\right) \approx$ $\operatorname{Corr}\left(-g \eta_{x}, f V\right) \approx-0.8$. Thus the modeled current geo- strophically adjusts (within 1-2 days) to changes in the pressure field brought about by the assimilation of temperatures. On the other hand, Fig. 12 shows also that the ageostrophic terms $\left[K_{M}(U, V)_{z}\right]_{z}$ are mostly balanced by the tendency terms $\partial(U, V) / \partial t$ : $\operatorname{Corr}\left[\left(K_{M} U_{z}\right)_{z}, U_{t}\right] \approx$ 0.96 and $\operatorname{Corr}\left[\left(K_{M} V_{z}\right)_{z}, V_{t}\right] \approx 0.92$. For the near-surface grid layer, $\left[K_{M}(U, V)_{z}\right]_{z} \approx\left(\tau^{o x, y}-\tau_{b}^{x, y}\right)$, where $\tau^{o}$ denotes wind stress and $\tau_{b}$ shear stress at base of the layer. Because $\tau^{o x, y}$ is identical for experiments $\mathrm{A}$ and $\mathrm{B}$, 
(b)
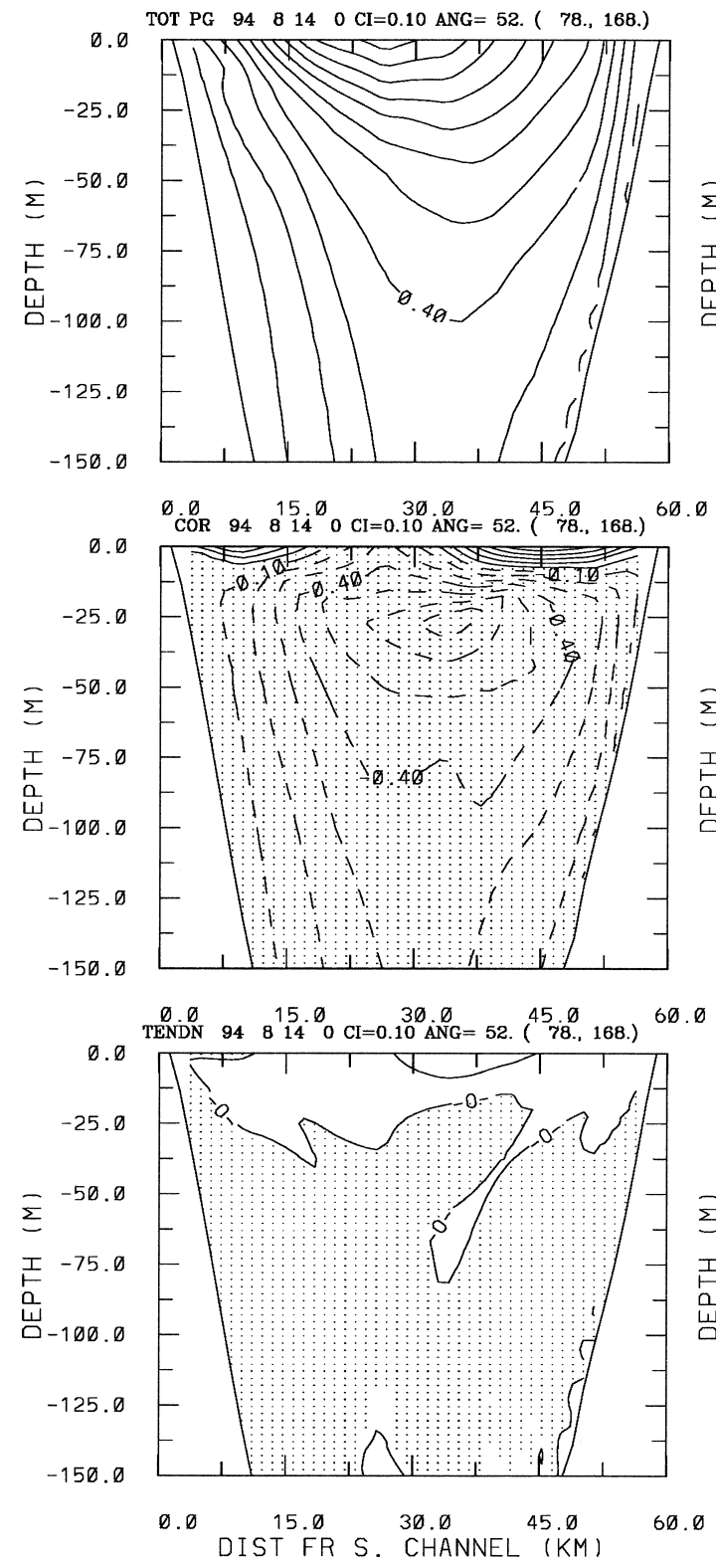
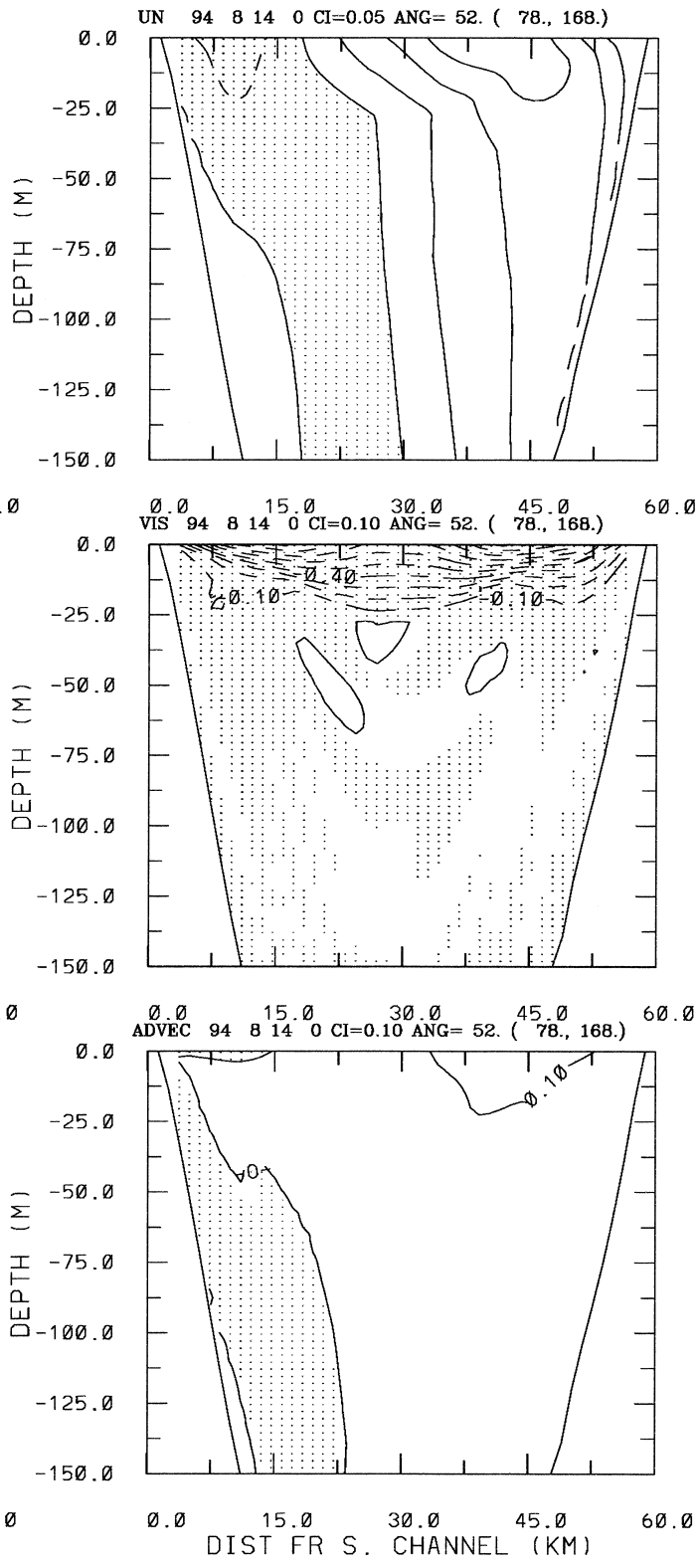

FIG. 13. (Continued)

$\delta_{\mathrm{AB}}\left\{\left[K_{M}(U, V)_{z}\right]_{z}\right\}=\delta_{\mathrm{AB}}\left(-\tau_{b}^{x, y}\right)$. When this latter quantity is positive (negative), the velocity profile must be increasingly sheared and more poleward (equatorward) with depth for experiment A. Figure 12 shows that $\delta_{\mathrm{AB}}\left(-\tau_{b}\right)$ is generally $>0$. Thus data assimilation on average produces more poleward surface acceleration, against the wind (i.e., the green curves in top panels of Figs. 10 and 12 are generally of opposite signs). The acceleration is more intense from May through August, consistent with the generally more poleward PG force due to the increased east-to-west temperature difference $\left(\Delta T_{\text {BARB-PAIN }} \approx 5^{\circ} \mathrm{C}\right)$.

Figure 13 shows the balance terms for experiments
A and B in the same vertical transect as Fig. 9, for the summer when effects of assimilation are strongest. The figure's top-right panel shows the along-channel velocity (i.e., $U_{n}$ ). To show details, we plot only the nearsurface $150 \mathrm{~m}$. The $U_{n}$ in experiment $\mathrm{A}$ is more intense (double), and there are regions near the surface where the magnitude increases with depth. The differences in the velocities between experiments A and B can be understood in terms of the differences in the forces that drive them. The along-channel pressure gradient $\left(\mathrm{PG}_{n}\right)$ is poleward across the whole channel width for experiment B-a "single cell" $\mathrm{PG}_{n}$ structure. This single-cell $\mathrm{PG}_{n}$ structure is caused by a channelwide, westward 
NDBC 46054 Wind Stress $\left(\mathrm{N} / \mathrm{m}^{\wedge} 2\right)$

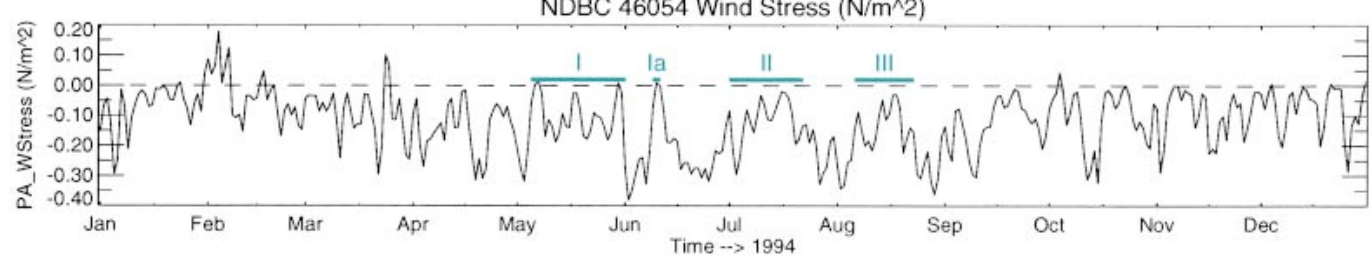

SMOF \& Exp.B Temperatures (Deg C)

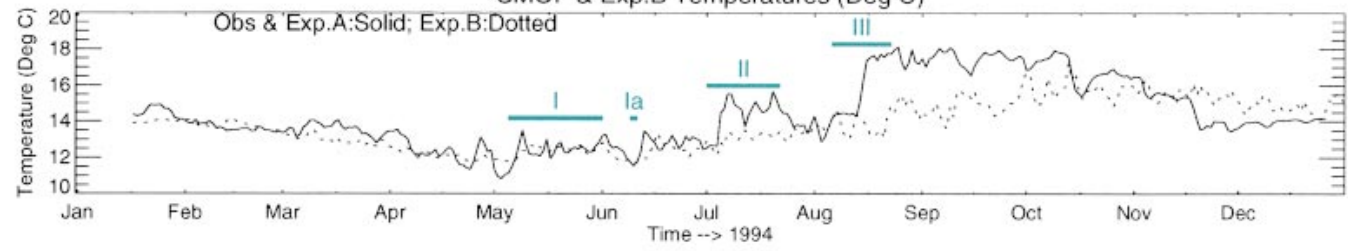

ROOF \& Exp.B Temperatures (Deg C)

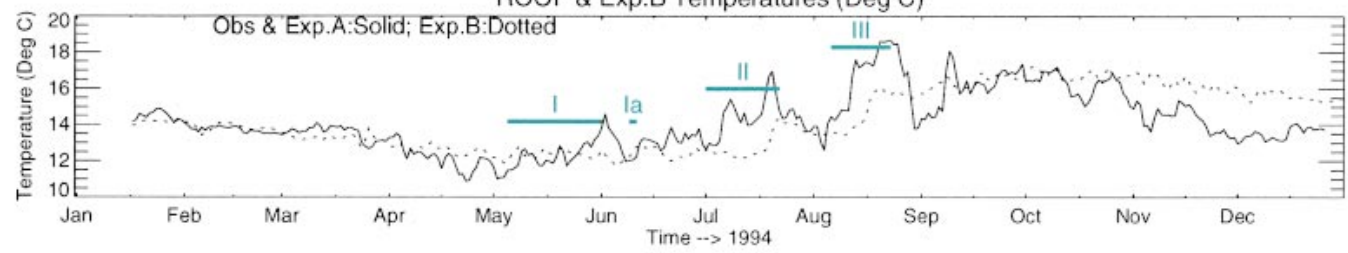

SMIN \& Exp.B Temperatures (Deg C)

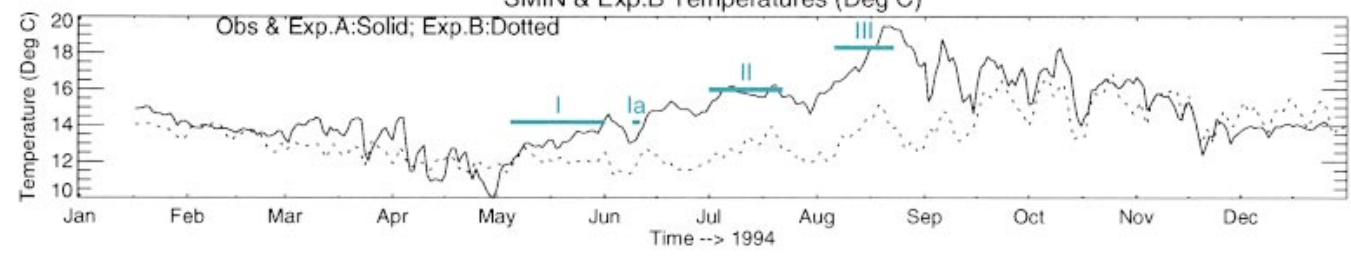

SMOF \& Exp.A Currents $(\mathrm{m} / \mathrm{s})$

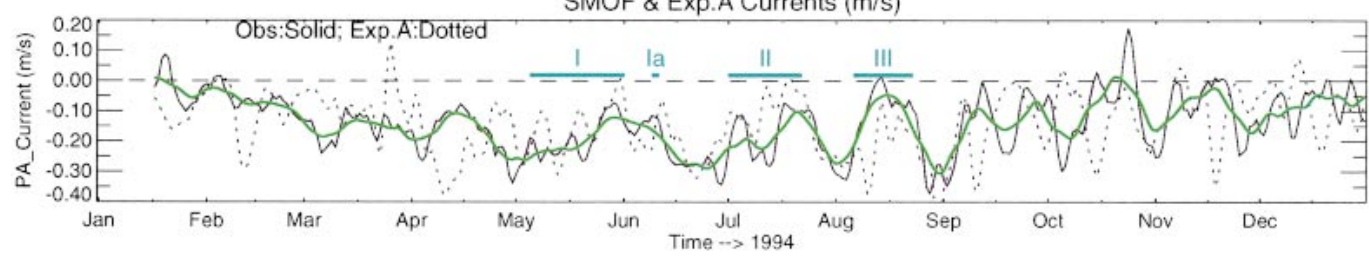

ROOF \& Exp.A Currents $(\mathrm{m} / \mathrm{s})$

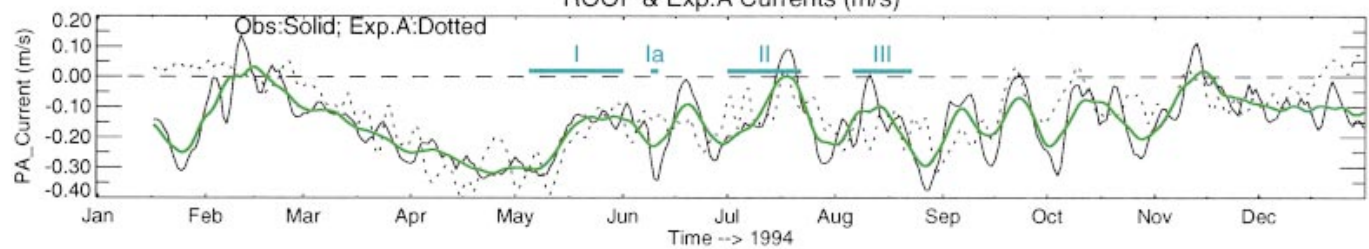

SMOF/SMIN PG \& Wind_Shear $\left(\mathrm{m} / \mathrm{s}^{\wedge} 2\right)$

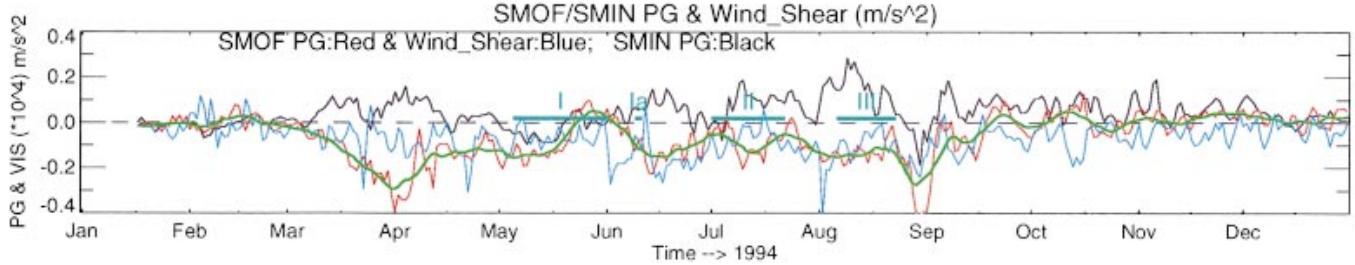

FIG. 14. Time series of (from top to bottom) NDBC 46054 wind stress; observed and expt B temperatures at SMOF, ROOF, and SMIN; observed and expt A principal-axis currents at SMOF and ROOF; and pressure gradient and vertical shear normal to a cross-channel section just east of SMOF and SMIN. Periods during which the wind relaxes in summer are indicated by horizontal lines marked I, Ia, II, and III as discussed in text. 
progression of warm water from the east and south. For experiment $\mathrm{A}, \mathrm{PG}_{n}$ is poleward on the right (north), with a magnitude that is $50 \%$ higher than that for experiment $\mathrm{B}$, and equatorward on the left (south) of the channela "double cell" structure. Also, the strong poleward $\mathrm{PG}_{n}$ is "trapped" along the northern coast of the channel and is caused by the heat input in data assimilation especially along the northern coast and east and south (ANMI and BARB). The equatorward pressure gradient along the southern coast is caused by assimilation as offshore waters near the station SMOF warms in response to periods of wind relaxation (see below). It drives equatorward currents along the southern coast, hence also a stronger cyclone (Fig. 8).

In experiment B (Fig. 13b), the tendency and advective terms are small, so that the primary balance is between $\mathrm{PG}_{n}$, Coriolis force, and the vertical stress divergence term $\left[K_{M}\left(U_{n}\right)_{z}\right]_{z}$. Near the surface, $\left[K_{M}\left(U_{n}\right)_{z}\right]_{z}$, is proportional to the wind shear, which drives southward Ekman currents; this in turns produces poleward Coriolis. A consequence of the single-cell $\mathrm{PG}_{n}$ structure in experiment $\mathrm{B}$ is that the strong $\mathrm{PG}_{n}$ near the center of the channel overwhelms the Ekman currents and drives equatorward Coriolis there. Below the wind shear layer, $z<-30 \mathrm{~m}$, geostrophic balance holds: Coriolis $\approx \mathrm{PG}_{n}$.

In experiment A (Fig. 13a), the tendency and advective terms are significant. On the northern (right) half of the channel, poleward Coriolis and $\mathrm{PG}_{n}$ overcome equatorward wind shear, resulting in a net poleward acceleration represented by the sum of tendency and advective terms. On the southern half of the channel, equatorward wind shear and $\mathrm{PG}_{n}$ now overcome poleward Coriolis, resulting in a net equatorward acceleration. In fact, in the southern half of the channel, wind shear and Coriolis nearly balance, leaving the equatorward $\mathrm{PG}_{n}$ as the net acceleration agent. The "assimilated" $\mathrm{PG}_{n}$ clearly plays a determining role in the circulation dynamics. From the $U_{n}$ profiles of both spring and summer (Figs. 9a and 13a), the Rossby numbers $\approx$ 0.5 , which confirms the significance of the tendency and advective terms.

\section{c. The origin of the equatorward $P G_{n}$ off the channel's southern coast}

The double-cell $\mathrm{PG}_{n}$ structure of experiment A (Fig. 13a) maintains a strong cyclone (and currents) in better agreement with observations. The poleward $\mathrm{PG}_{n}$ trapped against the northern coast is due to temperatures assimilated along the northern and eastern portions of the channel. We now explain the origin of equatorward $\mathrm{PG}_{n}$ along the southern coast.

Figure 14 shows time series of principal-axis wind stress at 46054, 5-m temperatures (observed) at SMOF, ROOF, and SMIN, and also principal-axis currents (observed) at SMOF and ROOF. In the temperature plots, we also show the model temperatures from experiment
B (those from expt A almost exactly coincide with the observed). In the currents plots, results from experiment $A$ are shown. In the bottom panel, we show the $\left\langle\int_{-10 \mathrm{~m}}^{0}\right.$ $\left.\left[-\left(p / \rho_{o}\right)_{y}\right] d z / 10 \mathrm{~m}\right\rangle$, the near-surface $\mathrm{PG}_{n}$ averaged over a 10-m depth and also over the southern (red) and northern (black) halves of the western channel entrance. The entrance is taken as a north-south line approximately joining SMOF and SMIN. The panel also shows the shear term $\left\langle\left(\tau^{o y}-\tau_{-10 \mathrm{~m}}^{y}\right) / 10 \mathrm{~m}\right\rangle$ (blue) averaged over the southern half of the channel. The shear term for the northern half is similar but weaker (not shown). Also, thick green curves in the last three panels show lowpassed time-series of the currents and pressure gradient when periods shorter than 10 days are removed. We focus on the period May/September during which the double-cell $\mathrm{PG}_{n}$ structure exists.

Figure 14 shows three prolonged periods $(\approx 20$ days $)$ and one shorter period of wind relaxations during the summer of 1994. Period I was when the wind stress dropped from its peak of about $-0.3 \mathrm{~Pa}$ around 5 May to about $-0.15 \mathrm{~Pa}$. The "relaxed" wind lasted through 1 June when the wind peaked again to about $-0.37 \mathrm{~Pa}$. Apart from a brief period (1-2 days) of relaxation around 10 June (period Ia), the strong wind $(\approx-0.3 \mathrm{~Pa})$ persisted through 1 July. Similar prolonged relaxations occurred from 1 July through 22 July (period II) and again from 6 August through 31 August (period III). These relaxation periods are indicated by horizontal lines in each panel in Fig. 14. The figure shows that at the beginning of each of these periods temperatures at SMOF rose in step, from $11^{\circ}$ to $13^{\circ} \mathrm{C}$ (period I), from $12^{\circ}$ to $13.5^{\circ} \mathrm{C}$ (Ia), from $13^{\circ}$ to $15.5^{\circ} \mathrm{C}$ (II), and from $14^{\circ}$ to $18^{\circ} \mathrm{C}$. These rises in temperature lag wind relaxations by 3-7 days, as can be seen by the shifts to the left of the horizontal lines relative to the beginning times of temperature rises. Similar rises and shifts can also be seen at ROOF and SMIN. Current at SMOF and ROOF also appear to respond to wind relaxation events. Currents generally weaken (and reverse at ROOF near the end of period II) during the relaxation periods, also with lags of a few days. The model generally reproduces these long-period episodic events during the summer. The correlation coefficients between the low-passed time series (periods shorter than 10 days removed) of observed and modeled currents at SMOF and ROOF are 0.52 and 0.74 , respectively (Fig. 7).

The wind shear time series mimics the wind stress time series. The PG at the southern coast (red) is generally equatorward in spring and summer and becomes more variable with a weak poleward mean in autumn and winter. The PG acceleration is particularly strong in spring and summer and is comparable to the wind shear term. The increased PG in spring and summer is consistent with the observed warming at SMOF. The correlation coefficient between the low-passed PG and observed or modeled current at SMOF (thick green curves) is high $(\approx 0.6)$, with PG leading currents by $1-$ 2 days. At the northern coast, the sign of PG generally 
reverses and the fluctuations are approximately opposite (i.e., $180^{\circ}$ out of phase) to those in the south. Therefore, because neither experiment $\mathrm{B}$ (wind alone) nor experiment $\mathrm{F}$ (assimilation alone) produces a strong cyclone, wind and assimilation-enhanced PG act in concert in a manner (as described above) that "spins" a stronger cyclone.

\section{Conclusions}

We study the sensitivity and dynamics of modeled surface currents in the SBC to moored temperature assimilation and forcings by various (spatial) approximations of winds. We show that the solution is sensitive to small-scale wind and wind curl distributions. Forcing using the standard wind archives such as the ECMWF yields poor results. A more recent study (C. M. Dong and L.-Y. Oey 2003, unpublished manuscript) suggests that a wind resolution of about $5 \mathrm{~km}$ is required to resolve adequately the rapidly varying spatial structure of the marine boundary layer in the SBC. In the present study, we conducted an experiment (expt B) forced by a wind distribution derived from all available buoy and land-based wind stations. We find that experiment B can capture the spatial and seasonal variations of the circulation, although the strength is weaker than observation. Momentum analysis suggests that the alongchannel PG serves as a dynamic index of the seasonal circulation. The PG is equatorward with the onset of spring from about late February through early May. The cause in the model is erosion and reversal of the poleward PG from the previous winter by a series of equatorward wind bursts east and south of the channel. The PG becomes poleward and strong in summer and autumn and then weakens in winter. The cause in the model is the large-scale differential wind curl as detailed in Oey (1999).

With assimilation (expt A), momentum analysis indicates a two-cell along-channel PG structure: a poleward PG along the northern coast and an equatorward PG along the southern coast. The two PG time series are approximately $180^{\circ}$ out of phase. The equatorward PG is due to observed warming episodes at SMOF, which we suggest are caused by wind-relaxation events in spring and summer. The oppositely directed PGs spin a stronger cyclone that improves the agreements between the modeled and observed currents in the channel. The model does not capture the short-period motions at ANMI (eastern channel entrance). In general, the model does poorly at the eastern channel (stations GOIN, CAIN, and ANMI; Fig. 7) for which remote forcing at longer-than-wind-band periods (10-30 days) has been identified in previous studies (Hickey 1992; Auad and Hendershott 1997; Hickey et al. 2003).

Acknowledgments. We thank Clive Dorman (who also provided the coastal wind data) and Myrl Hendershott for insights and many lively discussions. Barbara Hickey reminded us of the importance of remote forcing from the south and M. Wei assisted in some of the graphics. This work was funded by the Minerals Management Service and the Office of Naval Research (LYO). Computing was performed at the Geophysical Fluid Dynamics Laboratory, Princeton, New Jersey.

\section{REFERENCES}

Auad, G., and M. C. Hendershott, 1997: The low-frequency transport in the Santa Barbara Channel: Description and forcing. Cont. Shelf Res., 17, 779-802.

Bretherton, F. P., R. E. Davis, and C. B. Fandry, 1976: A technique for objective analysis and design of oceanographic experiments applied to MODE-73. Deep-Sea Res., 23, 559-582.

Chen, C.-S., and D.-P. Wang, 1999: Data assimilation model study of the Santa Barbara Channel. J. Geophys. Res., 104, $15727-$ 15472 .

__ and —_, 2000: Data assimilation model study of wind effects in the Santa Barbara Channel. J. Geophys. Res., 105, $22003-$ 22013.

Daley, R., 1993: Atmospheric Data Analysis. Cambridge University Press, $455 \mathrm{pp}$.

Davis, R. E., 1976: Predictability of sea surface temperature and sea level pressure anomalies over the North Pacific Ocean. J. Phys. Oceanogr., 3, 249-266.

Dever, E. P., M. C. Hendershott, and C. D. Winant, 1998: Statistical aspects of surface drifter observations of circulation in the Santa Barbara Channel. J. Geophys. Res., 103, 24 781-24 797.

Dorman, C. E., and C. D. Winant, 2000: The structure and variability of the marine atmosphere around the Santa Barbara Channel. Mon. Wea. Rev., 128, 261-282.

Harms, S., and C. D. Winant, 1998: Characteristic patterns of the circulation in the Santa Barbara Channel. J. Geophys. Res., 103, 3041-3065.

Hickey, B. M., 1979: The California Current System: Hypotheses and facts. Progress in Oceanography, Vol. 8, Pergamon, 191-279. , 1992: Circulation over the Santa Monica-San Pedro basin and shelf. Progress in Oceanography, Vol. 30, Pergamon, 37-115.

- E. L. Dobbins, and S. E. Allen, 2003: Local and remote forcing of currents and temperature in the central Southern California Bight. J. Geophys. Res., 108, 3081, doi:10.1029/2000JC000313.

Large, W. G., and S. Pond, 1981: Open ocean momentum flux measurements in moderate to strong winds. J. Phys. Oceanogr., 11, 324-336.

Levitus, S., 1982: Climatological Atlas of the World Ocean. NOAA Prof. Paper 13, 174 pp. and 17 microfiche.

__ 1994: World Ocean Atlas 1994. CD-Rom sets. National Oceanographic Data Center Informal Rep. 13.

Mellor, G. L., 1993: User's guide. [Available online at http:// www.aos.princeton.edu/WWWPUBLIC/htdocs.pom.]

Munchow, A., 2000: Wind stress curl forcing of the coastal ocean near Point Conception, California. J. Phys. Oceanogr., 30, 12651280.

Oey, L.-Y., 1996: Flow around a coastal bend: A model of the Santa Barbara Channel eddy. J. Geophys. Res., 101, 16 667-16 682. , 1998: Eddy energetics in the Faroe-Shetland Channel. Cont. Shelf Res., 17, 1929-1944.

, 1999: A forcing mechanism for the poleward flow off the southern California coast. J. Geophys. Res., 104, 13 529-13 539.

__ 2000: Understanding and predicting coastal circulation based on strategically located observation stations. Proc. Second Int. Ocean and Atmosphere Conf., Taipei, Taiwan, Central Weather Bureau, 201-216.

, and P. Chen, 1992: A nested-grid model simulation of the Norwegian coastal current. J. Geophys. Res., 97, $20063-20086$. 
_ D.-P. Wang, T. Hayward, C. Winant, and M. Hendershott, 2001 Upwelling and cyclonic regimes of the near-surface circulation in the Santa Barbara Channel. J. Geophys. Res., 106, 9213-9222.

Smagorinsky, J., 1963: General circulation experiments with the primitive equations. Part I: The basic experiment. Mon. Wea. Rev., 91, 99-164.
Wang, D.-P., 1997: Effects of small-scale wind on coastal upwelling with application to Point Conception. J. Geophys. Res., 102, 15 555-15 566.

Winant, C. D., and C. E. Dorman, 1997: Seasonal patterns of surface wind stress and heat flux over the Southern California Bight. $J$. Geophys. Res., 102, 5641-5653. 